Universidad

:\% de Alcalá

\title{
BIBLIOTECA
}

Document downloaded from the institutional repository of the University of Alcala: https://ebuah.uah.es/dspace/

This is a postprint version of the following published document:

Gómez et al., 2019. Molecular Design of Cyclopentadienyl Tantalum Sulfide Complexes. Inorganic chemistry, 58(9), pp.5593-5602.

Available at https://doi.org/10.1021/acs.inorgchem.8b03563

(c) 2019 American Chemical Society.
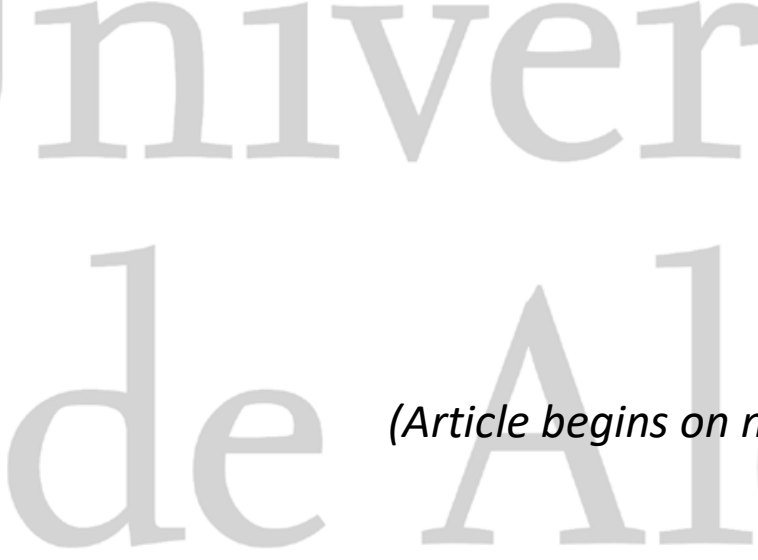

(Article begins on next page)

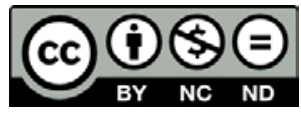

This work is licensed under a

Creative Commons Attribution-NonCommercial-NoDerivatives

4.0 International License. 


\section{Molecular Design of Cyclopentadienyl Tantalum Sulfide Complexes}

Manuel Gómez, ${ }^{a}$ Juan Ignacio González-Pérez, ${ }^{a}$ Cristina Hernández-Prieto, ${ }^{a}$ Avelino Martín, ${ }^{a}$ Miguel Mena, ${ }^{a}$ Cristina Santamaría, ${ }^{a} *$ and Manuel Temprado ${ }^{b}$

Instituto de Investigación Química “Andrés M. del Río" (IQAR), Universidad de Alcalá, Campus Universitario, E-28805 Alcalá de Henares, Madrid, Spain. ${ }^{a}$ Departamento de Química Orgánica

y Química Inorgánica, ${ }^{\mathrm{b}}$ Departamento de Química Analítica, Química Física e Ingeniería Química. 


\section{ABSTRACT}

Use of $\left(\mathrm{Me}_{3} \mathrm{Si}\right)_{2} \mathrm{~S}$ and $\left[\mathrm{Ta}\left(\eta^{5}-\mathrm{C}_{5} \mathrm{Me}_{5}\right) \mathrm{Cl}_{4}\right](\mathbf{1})$ in a 4:3 ratio afforded the trimetallic sulfide cluster $\left[\mathrm{Ta}_{3}\left(\eta^{5}-\mathrm{C}_{5} \mathrm{Me}_{5}\right)_{3} \mathrm{Cl}_{3}\left(\mu_{3}-\mathrm{Cl}\right)(\mu-\mathrm{S})_{3}\left(\mu_{3}-\mathrm{S}\right)\right]$ (2) with loss of $\mathrm{SiClMe}_{3}$. A similar reaction between $\mathbf{1}$, $\mathrm{TaCl}_{5}$ and $\left(\mathrm{Me}_{3} \mathrm{Si}\right)_{2} \mathrm{~S}$ in 2:1:4 ratio resulted in the analogous complex $\left[\mathrm{Ta}_{3}\left(\eta^{5}-\mathrm{C}_{5} \mathrm{Me}_{5}\right)_{2} \mathrm{Cl}_{4}\left(\mu_{3}-\right.\right.$ $\left.\mathrm{Cl})\left(\mu_{-} \mathrm{S}\right)_{3}\left(\mu_{3}-\mathrm{S}\right)\right](3)$. Single crystal X-ray diffraction analyses of $\mathbf{2}$ and $\mathbf{3}$ showed in all cases trinuclear tantalum sulfide clusters. On the other hand, thermal treatment of 2 with $\mathrm{SiH}_{3} \mathrm{Ph}$ generated very cleanly the dinuclear tantalum(IV) sulfide complex $\left[\mathrm{Ta}_{2}\left(\eta^{5}-\mathrm{C}_{5} \mathrm{Me}_{5}\right)_{2} \mathrm{Cl}_{2}(\mu-\mathrm{S})_{2}\right]$ (4) in a quantitative way. Likewise, we found that $\mathbf{4}$ was synthesized more easily by a one-pot reaction of $1,\left(\mathrm{Me}_{3} \mathrm{Si}\right)_{2} \mathrm{~S}$ and $\mathrm{SiH}_{3} \mathrm{Ph}$ in toluene. Reactions of 4 with a series of alkylating reagents rendered the dinuclear peralkylated sulfide complexes $\left[\mathrm{Ta}_{2}\left(\eta^{5}-\mathrm{C}_{5} \mathrm{Me}_{5}\right)_{2} \mathrm{R}_{2}(\mu-\mathrm{S})_{2}\right](\mathrm{R}=$ Me 5, Et 6, $\mathrm{CH}_{2} \mathrm{SiMe}_{3}$ 7, $\mathrm{C}_{3} \mathrm{H}_{5} \mathbf{8}, \mathrm{Ph}$ 9). Single crystal X-ray diffraction analyses of 4, 5 and 9 showed in all cases a trans disposition of the chloro or alkyl substituents. The short distances TaTa (2.918(1)-2.951(1) ̊) along with DFT calculations indicate a $\sigma$-Ta-Ta interaction. Complexes 5, 6 and $\mathbf{8}$ undergo trans-cis isomerization and mechanistic proposals are discussed based on DFT calculations. 


\section{INTRODUCTION}

Metal sulfide complexes (M-S) have demonstrated a great importance in the area of transition metal clusters and in the design of chemical systems inspired by biological assemblies. ${ }^{1,2,3}$ Related to this latter, it is noteworthy the presence of sulfide clusters with cube-type or incomplete cubane-type $e^{4,5,6}$ structures at the active sites in most of the metalloproteins of biological significance such as nitrogenase, hydrogenase... The knowledge of the threedimensional structures of well defined and characterized M-S model complexes has provided impressive advances in our understanding about action modes of these active enzymes. ${ }^{7,8}$ In this regard, the chemistry of soluble transition-metal sulfides has strengthened this pursuit. ${ }^{9}$

The incorporation of sulfur groups to cyclopentadienyl-transition metal moieties affords an accessible entry to di- and polynuclear sulfide transition metal complexes, ${ }^{10,11}$ where the distinctive chemical and electronic properties of the cyclopentadienyl ring make it possible a better isolation, spectroscopic characterization, and thereby to explore further reactivity on these sulfide species.

We reported previously the syntheses of cubane-type or incomplete cubane-type group $5(\mathrm{Nb}$, Ta) sulfide clusters, which involved the distorted octahedral imido compounds $\left[\mathrm{MCl}_{3}(\mathrm{NR}) \mathrm{py}_{2}\right]$ $(\mathrm{M}=\mathrm{Nb}, \mathrm{Ta})$ as building block complexes and the hexamethyldisilathiane reagent, $\left(\mathrm{Me}_{3} \mathrm{Si}\right)_{2} \mathrm{~S}$, as sulfur source. ${ }^{12}$ However, the scarce solubility exhibited by these species prevented the exploration on their further reactivity. Aiming at developing soluble metal sulfur chemistry, we decided to replace the imido moiety by a pentamethylcyclopentadienyl group as auxiliary ligand. On the basis of this strategy, we have carried out a rational synthetic method, leading to the formation of trinuclear pentamethylcyclopentadienyl tantalum(V) sulfide complexes, $\left[\mathrm{Ta}_{3}\left(\eta^{5}-\right.\right.$ 
$\left.\left.\mathrm{C}_{5} \mathrm{Me}_{5}\right)_{3-\mathrm{x}} \mathrm{Cl}_{3+\mathrm{x}}\left(\mu_{3}-\mathrm{Cl}\right)(\mu-\mathrm{S})_{3}\left(\mu_{3}-\mathrm{S}\right)\right](\mathrm{x}=0,1)$. Furthermore, the easy and systematic access of dinuclear tantalum(IV) compounds comprising the fragment $\left[\mathrm{Ta}\left(\eta^{5}-\mathrm{C}_{5} \mathrm{Me}_{5}\right)(\mu-\mathrm{S})\right]_{2}$ is also reported. 


\section{EXPERIMENTAL SECTION}

General Considerations. All manipulations were carried out under a dry argon atmosphere using Schlenk-tube and cannula techniques or in a conventional argon-filled glovebox. Solvents were carefully refluxed over the appropriate drying agents and distilled prior to use: $\mathrm{C}_{6} \mathrm{D}_{6}$ and hexane $\left(\mathrm{Na} / \mathrm{K}\right.$ alloy), $\mathrm{CDCl}_{3}\left(\mathrm{CaH}_{2}\right)$, tetrahydrofurane $(\mathrm{Na} /$ benzophenone) and toluene $(\mathrm{Na})$. Starting material $\left[\mathrm{Ta}\left(\eta^{5}-\mathrm{C}_{5} \mathrm{Me}_{5}\right) \mathrm{Cl}_{4}\right]$ was prepared following reported procedure for titanium, ${ }^{13}$ organolithium reagents $\mathrm{LiCH}_{2} \mathrm{SiMe}_{3},{ }^{14}$ and organosilicon reductant 1,4-bis(trimethylsilyl)-1,4diaza-2,5-cyclohexadiene ${ }^{15}$ were synthesized according to published procedures. Grignard reagents $\mathrm{MgClR}\left(\mathrm{R}=\mathrm{Me}, 3 \mathrm{M}\right.$ in thf; $\mathrm{CH}_{2} \mathrm{Me}, \mathrm{C}_{3} \mathrm{H}_{5}, \mathrm{Ph}, 2 \mathrm{M}$ in thf), $\mathrm{TaCl}_{5},\left(\mathrm{Me}_{3} \mathrm{Si}\right)_{2} \mathrm{~S}$ and $\mathrm{SiH}_{3} \mathrm{Ph}$ were purchased from Aldrich and were used without further purification. Microanalyses (C, H, N, S) were performed in a LECO CHNS-932 microanalyzer. Samples for IR spectroscopy were prepared as $\mathrm{KBr}$ pellets and recorded on the Perkin-Elmer IR-FT Frontier spectrophotometer $\left(4000-400 \mathrm{~cm}^{-1}\right) .{ }^{1} \mathrm{H}$ and ${ }^{13} \mathrm{C}$ NMR spectra were obtained by using Varian NMR System spectrometers: Unity-300 Plus, Mercury-VX, Unity-500 and Bruker 400 Ultrashield, and reported with reference to solvent resonances. Repeated attempts to obtain better elemental analysis for complexes $\mathbf{2 , 3 , 4 , 5}$ and $\mathbf{8}$ were unsuccessful.

Synthesis of $\left[\mathrm{Ta}_{3}\left(\eta^{5}-\mathrm{C}_{5} \mathrm{Me}_{3}\right)_{3} \mathrm{Cl}_{3}\left(\mu_{3}-\mathrm{Cl}\right)(\mu-\mathrm{S})_{3}\left(\mu_{3}-\mathrm{S}\right)\right]$ (2). A toluene (5 mL) solution of $\left(\mathrm{Me}_{3} \mathrm{Si}\right)_{2} \mathrm{~S}(0.78 \mathrm{~g}, 4.37 \mathrm{mmol})$ was added to $\left[\mathrm{Ta}\left(\eta^{5}-\mathrm{C}_{5} \mathrm{Me}_{5}\right) \mathrm{Cl}_{4}\right](\mathbf{1})(1.50 \mathrm{~g}, 3.27 \mathrm{mmol})$ in toluene $(50-60 \mathrm{~mL})$ placed into a Carius tube $(150 \mathrm{~mL})$ with a Young's valve. The argon pressure was reduced, and the reaction mixture was heated to $100{ }^{\circ} \mathrm{C}$ for 72 hours. The resulting solution was filtered, and the solvent removed under vacuum to afford $\mathbf{2}$ as a yellow-green solid (Yield: $1.26 \mathrm{~g}, 95 \%) . \mathrm{IR}\left(\mathrm{KBr}, \mathrm{cm}^{-1}\right): \quad \bar{v}=2982(\mathrm{~m}), 2961(\mathrm{~m}), 2920(\mathrm{~s}), 1478(\mathrm{~m}), 1426(\mathrm{~m})$, 1377 (s), 1022 (vs), 919 (m), 843 (m), 496 (s). ${ }^{1} \mathrm{H}$ NMR (500 MHz, $\mathrm{C}_{6} \mathrm{D}_{6}$ ): $\delta=1.90$ (s, 45H, 
$\left.\mathrm{C}_{5} \mathrm{Me}_{5}\right) \cdot{ }^{13} \mathrm{C}\left\{{ }^{1} \mathrm{H}\right\}$ NMR $\left(125 \mathrm{MHz}, \mathrm{C}_{6} \mathrm{D}_{6}\right): \delta=123.6\left(C_{5} \mathrm{Me}_{5}\right), 12.1\left(\mathrm{C}_{5} M e_{5}\right)$. Elemental analysis

(\%) calcd. for $\mathrm{C}_{30} \mathrm{H}_{45} \mathrm{Cl}_{4} \mathrm{~S}_{4} \mathrm{Ta}_{3}$ (1218.60): C, 29.57; H, 3.72; S 10.52; found: C, 30.25; H, 4.02; S 10.04 .

Synthesis of $\left.\left[\operatorname{Ta}_{3}\left(\eta^{5}-\mathrm{C}_{5} \mathrm{Me}\right)_{2}\right)_{4} \mathrm{Cl}_{4}\left(\mu_{3}-\mathrm{Cl}\right)(\mu-\mathrm{S})_{3}\left(\mu_{3}-\mathrm{S}\right)\right]$ (3). To a mixture of $\left[\mathrm{Ta}\left(\eta^{5}-\mathrm{C}_{5} \mathrm{Me}_{5}\right) \mathrm{Cl}_{4}\right]$ (1) $(0.40 \mathrm{~g}, 0.87 \mathrm{mmol})$ and $\mathrm{TaCl}_{5}(0.16 \mathrm{~g}, 0.44 \mathrm{mmol})$ in toluene $(50-60 \mathrm{~mL})$ placed in a Schlenk tube $(150 \mathrm{~mL})$ was added $\left(\mathrm{Me}_{3} \mathrm{Si}\right)_{2} \mathrm{~S}(0.31 \mathrm{~g}, 1.74 \mathrm{mmol})$ in toluene. The solution was left stirring at room temperature for 4 days to give an emerald-green suspension. The solid formed was filtered off, washed with hexane $(2 \times 5 \mathrm{~mL})$, and dried under vacuum to yield $0.34 \mathrm{~g}$ (70\%) of 3 as a green solid. IR $\left(\mathrm{KBr}, \mathrm{cm}^{-1}\right): \quad \bar{v}=2989$ (w), 2961 (w), 2909 (m), 1489 (m), 1432 (vs), 1376 (s), 1071 (w), 1019 (s), 808 (w), 466 (m). ${ }^{1} \mathrm{H}$ NMR (500 MHz, $\mathrm{CDCl}_{3}$ ): $\delta=2.45$ (s, 15H, $\left.\mathrm{C}_{5} M e_{5}\right), 2.41\left(\mathrm{~s}, 15 \mathrm{H}, \mathrm{C}_{5} M e_{5}\right) .{ }^{13} \mathrm{C}\left\{{ }^{1} \mathrm{H}\right\} \operatorname{NMR}\left(125 \mathrm{MHz}, \mathrm{CDCl}_{3}\right): \delta=130.2,128.2$ $\left(C_{5} \mathrm{Me}_{5}\right), 13.5,13.2\left(\mathrm{C}_{5} M e 5\right)$. Elemental analysis (\%) calcd. for $\mathrm{C}_{20} \mathrm{H}_{30} \mathrm{Cl}_{5} \mathrm{~S}_{4} \mathrm{Ta}_{3}$ (1118.82): $\mathrm{C}$, 21.47; H, 2.70; S 11.46; found: C, 22.01; H, 2.67; S 12.02.

\section{Synthesis of $\left[\mathrm{Ta}_{2}\left(\eta^{5}-\mathrm{C}_{5} \mathrm{Me}_{5}\right)_{2} \mathrm{Cl}_{2}(\mu-\mathrm{S})_{2}\right](4)$.}

METHOD A: $\mathrm{SiH}_{3} \mathrm{Ph}(0.27 \mathrm{~g}, 2.46 \mathrm{mmol})$ was added to a toluene solution $(40-45 \mathrm{~mL})$ of $\left[\mathrm{Ta}_{3}\left(\eta^{5}-\mathrm{C}_{5} \mathrm{Me}_{5}\right)_{3} \mathrm{Cl}_{3}\left(\mu_{3}-\mathrm{Cl}\right)(\mu-\mathrm{S})_{3}\left(\mu_{3}-\mathrm{S}\right)\right](2)(1.00 \mathrm{~g}, 0.82 \mathrm{mmol})$ placed into a Carius tube (100 $\mathrm{mL}$ ) with a Young's valve. The argon pressure was reduced, and the reaction mixture was heated to $100{ }^{\circ} \mathrm{C}$ for 72 hours, and then filtered. The resulting dark red solid $4(0.85 \mathrm{~g}, 90 \%)$ was obtained after drying under vacuum. METHOD B: To a suspension of $\left[\mathrm{Ta}\left(\eta^{5}-\mathrm{C}_{5} \mathrm{Me}_{5}\right) \mathrm{Cl}_{4}\right]$ (1) $(1.50 \mathrm{~g}, 3.27 \mathrm{mmol})$ in toluene $(30-40 \mathrm{~mL})$ placed in a Carious-tube $(100 \mathrm{~mL})$ with a Young's valve was added $\left(\mathrm{Me}_{3} \mathrm{Si}\right)_{2} \mathrm{~S}(0.78 \mathrm{~g}, 4.36 \mathrm{mmol})$ solved in toluene. The argon pressure was reduced, and the reaction mixture was heated to $90^{\circ} \mathrm{C}$ for 72 hours. After cooling the reaction 
mixture was added $\mathrm{SiH}_{3} \mathrm{Ph}(0.36 \mathrm{~g}, 3.27 \mathrm{mmol})$ and the reaction was heated once more to $90{ }^{\circ} \mathrm{C}$ for 72 hours. The resulting solution was filtered, and the solvent removed under vacuum to afford 4 as a dark red solid (Yield: $1.16 \mathrm{~g}, 92 \%) . \mathrm{IR}\left(\mathrm{KBr}, \mathrm{cm}^{-1}\right): \bar{v}=2978(\mathrm{w}), 2956(\mathrm{w}), 2907$ (m), 1489 (m), 1478 (m), 1376 (s), 1161 (w), 1024 (s), 802 (w), 440 (m). ${ }^{1} \mathrm{H}$ NMR (500 MHz, $\left.\mathrm{C}_{6} \mathrm{D}_{6}\right): \delta=2.05\left(\mathrm{~s}, 30 \mathrm{H}, \mathrm{C}_{5} M e_{5}\right) \cdot{ }^{13} \mathrm{C}\left\{{ }^{1} \mathrm{H}\right\} \mathrm{NMR}\left(125 \mathrm{MHz}, \mathrm{C}_{6} \mathrm{D}_{6}\right): \delta=117.6\left(C_{5} \mathrm{Me}_{5}\right), 12.6$ $\left(\mathrm{C}_{5} M e_{5}\right)$. Elemental analysis (\%) calcd. for $\mathrm{C}_{20} \mathrm{H}_{30} \mathrm{Cl}_{2} \mathrm{~S}_{2} \mathrm{Ta}_{2}$ (767.38): C, 31.30; H, 3.94; S 8.36; found: C, 31.78; H, 3.75; S 8.48.

Other procedures for the synthesis of $\left[\mathrm{Ta}_{2}\left(\eta^{5}-\mathrm{C}_{5} \mathrm{Me}_{5}\right)_{2} \mathrm{Cl}_{2}(\mu-\mathrm{S})_{2}\right]$ (4) from 2 with different reducing reagents are detailed below: METHOD C: N,N'-bis(trimethylsilyl)-1,4-diaza-2,5cyclohexadiene $(0.28 \mathrm{~g}, 1.23 \mathrm{mmol})$ was added to a toluene solution $(30-35 \mathrm{~mL})$ of $2(0.50 \mathrm{~g}$, $0.41 \mathrm{mmol}$ ) placed into a $100 \mathrm{~mL}$ Schlenk vessel. The reaction mixture was left stirring at room temperature for 1 day. After that, the resulting solution was filtered off, and the filtrate was concentrated to a few mililiters under vacuum. The solution was then cooled to $-20{ }^{\circ} \mathrm{C}$ to give a dark red crystalline solid. Compound $\mathbf{4}$ was obtained along with free pyrazine, in trace amounts. (Yield: $0.38 \mathrm{~g}, 80 \%)$. METHOD D: A toluene solution $(30-35 \mathrm{~mL})$ of $2(0.50 \mathrm{~g}, 0.41 \mathrm{mmol})$ was added to $\mathrm{Na} / \mathrm{Hg}(0.03 \mathrm{~g}, 1.30 \mathrm{mmol})$ in toluene placed into a $100 \mathrm{~mL}$ Schlenk vessel. The reaction mixture was left stirring at room temperature for 1 day. After that, the resulting solution was filtered off and the filtrate was concentrated under vacuum to a few milliliters. The solution was then cooled to $-20{ }^{\circ} \mathrm{C}$ to give dark red crystalline solid (Yield: $0.40 \mathrm{~g}, 85 \%$ ). METHOD E: $\mathrm{Mg}(0.02 \mathrm{~g}, 0.83 \mathrm{mmol})$ was added to a thf solution $(30-35 \mathrm{~mL})$ of $2(0.50 \mathrm{~g}, 0.41 \mathrm{mmol})$ placed into a $100 \mathrm{~mL}$ Schlenk vessel. The mixture reaction was left stirring at room temperature for 1 day. The solvent was then removed under vacuum, and the reaction crude was extracted with 
toluene $(3 \times 15 \mathrm{~mL})$. The filtrate was evaporated to dryness, and the resulting dark red solid was washed with hexane (3 x $10 \mathrm{~mL}$ ) and dried under vacuum (Yield $0.39 \mathrm{~g}, 83 \%$ ).

Synthesis of $\left[\mathrm{Ta}_{2}\left(\eta^{5}-\mathrm{C}_{5} \mathrm{Me}_{2}\right)_{2} \mathrm{Me}_{2}(\mu-\mathrm{S})_{2}\right]$ (5). To a solution of $4(0.50 \mathrm{~g}, 0.65 \mathrm{mmol})$ in toluene $(40 \mathrm{~mL})$ placed in a $100 \mathrm{~mL}$ Schlenk vessel was added a thf solution of MgClMe $(0.43$ $\mathrm{mL}, 1.30 \mathrm{mmol}$ ) at $0{ }^{\circ} \mathrm{C}$. After stirring for 24 hours at room temperature, the reaction mixture was filtered through celite, and the resulting solution was then evaporated to dryness to yield $\mathbf{5}$ as a green solid (Yield: $0.30 \mathrm{~g}, 64 \%)$. IR $\left(\mathrm{KBr}, \mathrm{cm}^{-1}\right): \quad \bar{v}=2973(\mathrm{w}), 2952(\mathrm{w}), 2906$ (s), $1488(\mathrm{w})$, 1427 (m), 1376 (s), 1258 (m), 1025 (s), 801 (vs), 480 (s). ${ }^{1} \mathrm{H}$ NMR (500 MHz, C6 $\left.\mathrm{D}_{6}\right): \delta=2.07$ (s, 30H, $\left.\mathrm{C}_{5} M e_{5}\right),-2.21(\mathrm{~s}, 6 \mathrm{H}, \mathrm{Ta}-M e) .{ }^{13} \mathrm{C}\left\{{ }^{1} \mathrm{H}\right\} \mathrm{NMR}\left(125 \mathrm{MHz}, \mathrm{C}_{6} \mathrm{D}_{6}\right): \delta=115.7\left(C_{5} \mathrm{Me}_{5}\right), 46.8$ (Ta-Me), $12.4\left(\mathrm{C}_{5} M e_{5}\right)$. Elemental analysis (\%) calcd. for $\mathrm{C}_{22} \mathrm{H}_{36} \mathrm{~S}_{2} \mathrm{Ta} 2$ (726.55): C, 36.37; $\mathrm{H}$, 4.99; S 8.83; found: C, 36.90; H, 4.84; S 7.89.

Synthesis of $\left[\operatorname{Ta}_{2}\left(\eta^{5}-C_{5} M_{5}\right)_{2} \mathbf{E t}_{2}(\mu-S)_{2}\right](6)$. To a solution of $4(0.50 \mathrm{~g}, 0.65 \mathrm{mmol})$ in toluene (40 mL) placed in a $100 \mathrm{~mL}$ Schlenk vessel was added a thf solution of MgClEt $(0.65 \mathrm{~mL}, 1.30$ $\mathrm{mmol})$ at $0{ }^{\circ} \mathrm{C}$. After stirring for 24 hours at room temperature, the reaction mixture was filtered through celite, and the solvent was then removed in vacuum to yield $\mathbf{6}$ as a brown solid (Yield: $0.29 \mathrm{~g}, 58 \%) . \mathrm{IR}\left(\mathrm{KBr}, \mathrm{cm}^{-1}\right): \quad \bar{v}=2978(\mathrm{w}), 2957$ (m), 2908 (s), 2854 (vs), 1485 (m), 1453 (vs), 1428 (vs), 1376 (s), 1260 (w), 1116 (m), 1027 (s), 799 (vs). ${ }^{1} \mathrm{H}$ NMR (500 MHz, C $6 \mathrm{D}_{6}$ ): $\delta=2.13$ $\left(\mathrm{s}, 30 \mathrm{H}, \mathrm{C}_{5} M e_{5}\right), 0.83\left(\mathrm{t}, 6 \mathrm{H}, J=10 \mathrm{~Hz}, \mathrm{Ta}-\mathrm{CH}_{2} M e\right),-1.67$ (c, 4H, $\left.J=10 \mathrm{~Hz}, \mathrm{Ta}-\mathrm{CH}_{2} \mathrm{Me}\right)$. ${ }^{13} \mathrm{C}\left\{{ }^{1} \mathrm{H}\right\}$ NMR $\left(125 \mathrm{MHz}, \mathrm{C}_{6} \mathrm{D}_{6}\right): \delta=115.8\left(C_{5} \mathrm{Me}_{5}\right), 63.0\left(\mathrm{Ta}-C_{2} \mathrm{Me}\right), 13.9\left(\mathrm{Ta}-\mathrm{CH}_{2} \mathrm{Me}\right), 12.3$ $\left(\mathrm{C}_{5} M e_{5}\right)$. Elemental analysis (\%) calcd. for $\mathrm{C}_{24} \mathrm{H}_{40} \mathrm{~S}_{2} \mathrm{Ta}_{2}$ (754.60): C, 38.20; H, 5.34; S 8.49; found: C, 38.25; H, 5.38; S 8.36. 
Synthesis of $\left[\mathrm{Ta}_{2}\left(\eta^{5}-\mathrm{C}_{5} \mathrm{Me}_{5}\right)_{2}\left(\mathrm{CH}_{2} \mathrm{SiMe}_{3}\right)_{2}(\mu-\mathrm{S})_{2}\right](7)$. A $100 \mathrm{~mL}$ Schlenk vessel was charged in the glovebox with $4(0.70 \mathrm{~g}, 0.91 \mathrm{mmol}), \mathrm{LiCH}_{2} \mathrm{SiMe}_{3}(0.17 \mathrm{~g}, 1.82 \mathrm{mmol})$, and toluene (50$60 \mathrm{~mL}$ ). After stirring for 24 hours at room temperature, the reaction mixture was filtered through a medium porosity glass frit, and the solvent was then removed in vacuum to yield $\mathbf{7}$ as a green solid (Yield: 0.69 g, 87\%). IR (KBr, cm ${ }^{-1}$ ): 3048 (w), 2953 (m), 2903 (m), 1487 (w), 1428 (m), 1376 (s), 1244 (s), 1164 (w), 1115 (w), 1028 (m), 933 (m), 846 (s), 713 (m), 434 (w). ${ }^{1} \mathrm{H}$ NMR $\left(500 \mathrm{MHz}, \mathrm{C}_{6} \mathrm{D}_{6}\right): \delta=2.12\left(\mathrm{~s}, 30 \mathrm{H}, \mathrm{C}_{5} \mathrm{Me}_{5}\right),-2.80\left(\mathrm{~s}, 4 \mathrm{H}, \mathrm{Me}_{3} \mathrm{SiCH}_{2}\right), 0.00(\mathrm{~s}, 18 \mathrm{H}$, $\left.\mathrm{Me}_{3} \mathrm{SiCH}_{2}\right) .{ }^{13} \mathrm{C}\left\{{ }^{1} \mathrm{H}\right\}$ NMR $\left(125 \mathrm{MHz}, \mathrm{C}_{6} \mathrm{D}_{6}\right): \delta=115.2\left(C_{5} \mathrm{Me}_{5}\right), 61.7\left(\mathrm{Me}_{3} \mathrm{SiCH}_{2}\right), 13.0$ ( $\mathrm{C}_{5} \mathrm{Me}$ ), $4.1\left(\mathrm{Me}_{3} \mathrm{SiCH}_{2}\right)$. Elemental analysis (\%) calcd. for $\mathrm{C}_{28} \mathrm{H}_{52} \mathrm{~S}_{2} \mathrm{Si}_{2} \mathrm{Ta}_{2}$ (870.91): C, 38.61; H, 6.02; S 7.36; found: C, 38.76; H, 5.65; S 7.14.

Synthesis of $\left[\mathrm{Ta}_{2}\left(\eta^{5}-\mathrm{C}_{5} \mathrm{Me}_{5}\right)_{2}\left(\mathrm{C}_{3} \mathrm{H}_{5}\right)_{2}(\mu-\mathrm{S})_{2}\right](8)$. To a solution of $4(0.80 \mathrm{~g}, 1.04 \mathrm{mmol})$ in toluene $(50-60 \mathrm{~mL})$ placed in a $150 \mathrm{~mL}$ Schlenk vessel was added a thf solution of $\mathrm{Mg}\left(\mathrm{C}_{3} \mathrm{H}_{5}\right) \mathrm{Cl}$ $(0.65 \mathrm{~mL}, 1.30 \mathrm{mmol})$ at $0{ }^{\circ} \mathrm{C}$. The reaction mixture was filtered through celite after stirring at room temperature for 24 hours, and the solvent was then removed in vacuum to yield $\mathbf{8}$ as a brown solid (Yield: $0.47 \mathrm{~g}, 93 \%)$. IR $\left(\mathrm{KBr}, \mathrm{cm}^{-1}\right): \quad \bar{v}=3078(\mathrm{w}), 2961$ (w), 2905 (m), $1684(\mathrm{w})$, $1609(\mathrm{w}), 1504(\mathrm{~m}), 1475(\mathrm{~m}), 1459$ (w), 1233 (w), 1212 (m), 1026 (vs), 1006 (vs), 843 (vs), 799 (m), $732(\mathrm{w}), 458(\mathrm{~m}) .{ }^{1} \mathrm{H}$ NMR $\left(500 \mathrm{MHz}, \mathrm{C}_{6} \mathrm{D}_{6}\right): \delta=5.19\left(\mathrm{~A}_{4} \mathrm{X}, 2 \mathrm{H},{ }^{3} J=11 \mathrm{~Hz}, \mathrm{C}_{3} \mathrm{H}_{5}\right), 1.80$ (s, 30H, $\left.\mathrm{C}_{5} M e_{5}\right), 1.70\left(\mathrm{~A}_{4} \mathrm{X}, 8 \mathrm{H},{ }^{3} J=11 \mathrm{~Hz}, \mathrm{C}_{3} \mathrm{H}_{5}\right) \cdot{ }^{13} \mathrm{C}\left\{{ }^{1} \mathrm{H}\right\}$ NMR $\left(125 \mathrm{MHz}, \mathrm{C}_{6} \mathrm{D}_{6}\right): \delta=124.0$ $\left(C_{5} \mathrm{Me}_{5}\right), 109.9\left(\mathrm{C}_{3} \mathrm{H}_{5}\right), 77.0\left(\mathrm{C}_{3} \mathrm{H}_{5}\right) .12 .3\left(\mathrm{C}_{5} M e_{5}\right)$. Elemental analysis (\%) calcd. for $\mathrm{C}_{26} \mathrm{H}_{40} \mathrm{~S}_{2} \mathrm{Ta}_{2}$ (778.62): C, 40.11; H, 5.18; found: C, 39.51; H, 5.44.

Synthesis of $\left[\operatorname{Ta}_{2}\left(\eta^{5}-\mathrm{C}_{5} \mathrm{Me}_{5}\right)_{2} \mathbf{P h}_{2}(\mu-\mathrm{S})_{2}\right](\mathbf{9})$. To a solution of $\mathbf{4}(0.50 \mathrm{~g}, 0.65 \mathrm{mmol})$ in toluene (40 mL) placed in a $100 \mathrm{~mL}$ Schlenk vessel was added a thf solution of $\mathrm{Mg}\left(\mathrm{C}_{6} \mathrm{H}_{5}\right) \mathrm{Cl}(0.65 \mathrm{~mL}$, 
$1.30 \mathrm{mmol}$ ) at $0{ }^{\circ} \mathrm{C}$. After stirring for 24 hours at room temperature, the reaction mixture was filtered through celite, and the solvent was then removed in vacuum to yield $\mathbf{9}$ as an orange brownish solid (Yield: $0.45 \mathrm{~g}, 81 \%)$. IR $\left(\mathrm{KBr}, \mathrm{cm}^{-1}\right): \quad \bar{v}=3048$ (m), $2956(\mathrm{~m}), 2907$ (s), 2850 (w), $1478(\mathrm{~m}), 1453$ (m), 1414 (m), 1377 (s), 1063 (s) 1026 (s), 760 (s), 728 (s), 700 (s), 438 (m). ${ }^{1} \mathrm{H}$ NMR $\left(500 \mathrm{MHz}, \mathrm{C}_{6} \mathrm{D}_{6}\right): \delta=6.74-6.86(\mathrm{~m}, 10 \mathrm{H}, \mathrm{Ph}), 2.12\left(\mathrm{~s}, 30 \mathrm{H}, \mathrm{C}_{5} M e_{5}\right) .{ }^{13} \mathrm{C}\left\{{ }^{1} \mathrm{H}\right\} \mathrm{NMR}$ (125 MHz, $\left.\mathrm{C}_{6} \mathrm{D}_{6}\right): \delta=134.1,128.3,126.3,126.1(\mathrm{Ph}), 117.6\left(C_{5} \mathrm{Me}_{5}\right), 12.4\left(\mathrm{C}_{5} M e_{5}\right)$. Elemental analysis (\%) calcd. for $\mathrm{C}_{32} \mathrm{H}_{40} \mathrm{~S}_{2} \mathrm{Ta}_{2}$ (850.69): C, 45.18; H, 4.74; $\mathrm{S}$ 7.54; found: C, 45.18; $\mathrm{H}$, 4.87; S 7.06.

Trans/cis isomerization of $\left.\left[\mathrm{Ta}_{2}\left(\eta^{5}-\mathrm{C}_{5} \mathrm{Me}\right)_{2}\right)_{2} \mathrm{Me}_{2}(\mu-\mathrm{S})_{2}\right]$ (5). A transparent 5-mm NMR tube was charged with 5-trans $(0.02 \mathrm{~g}, 0.027 \mathrm{mmol})$ and $0.60 \mathrm{ml}$ of $\mathrm{C}_{6} \mathrm{D}_{6}$. After acquiring the ${ }^{1} \mathrm{H}$ NMR spectrum at room temperature the sample was placed in an oil bath at diferent tempertures and subsequently spectra were acquired periodically until no futher change was observed. Upon monitoring after heating at $\approx 95^{\circ} \mathrm{C}$, the mixture of isomers trans/cis was detected in aprox. $63: 37$ ratio. This isomerization was no observed when the experiment was performed with an amberized NMR tube. ${ }^{1} \mathrm{H}$ NMR $\left(500 \mathrm{MHz}, \mathrm{C}_{6} \mathrm{D}_{6}\right)$ : 5-trans: $\delta=2.07$ (s, 30H, $\left.\mathrm{C}_{5} M e_{5}\right),-2.21(\mathrm{~s}$, 6H, Ta-Me); 5-cis: $\delta=2.10$ (s, 30H, $\left.\mathrm{C}_{5} M e_{5}\right),-1.21$ (s, 6H, Ta-Me).

Trans/cis isomerization of $\left[\operatorname{Ta}_{2}\left(\eta^{5}-\mathrm{C}_{5} \mathrm{Mes}_{2}\right)_{2} \mathrm{Et}_{2}(\mu-\mathrm{S})_{2}\right](6)$. In a 10-mL glass vial, $0.02 \mathrm{~g}$ of 6 (0.028 mmol) was solved in $0.6 \mathrm{~mL}$ of $\mathrm{C}_{7} \mathrm{D}_{8}$ and subsequently transferred to a amber-stained or transparent 5-mm NMR tube. Upon monitoring by ${ }^{1} \mathrm{H}$ NMR spectroscopy the heating of the sample until $\approx 95{ }^{\circ} \mathrm{C}$, a mixture of isomers trans/cis was detected in aprox. 66:34 ratio. ${ }^{1} \mathrm{H}$ NMR

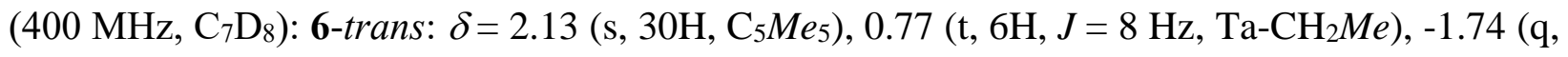


$\left.4 \mathrm{H}, J=8 \mathrm{~Hz}, \mathrm{Ta}-\mathrm{CH}_{2} \mathrm{Me}\right)$; 6-cis: $\delta=2.10\left(\mathrm{~s}, 30 \mathrm{H}, \mathrm{C}_{5} M e_{5}\right), 0.87$ (t, 6H, $\left.J=8 \mathrm{~Hz}, \mathrm{Ta}-\mathrm{CH}_{2} M e\right)$, $0.52\left(\mathrm{q}, 4 \mathrm{H}, J=8 \mathrm{~Hz}, \mathrm{Ta}-\mathrm{CH}_{2} \mathrm{Me}\right)$.

Crystal structure determination of complexes 2-5, and 9. Crystals of 2-4 and 9 were obtained by slow cooling at $-20^{\circ} \mathrm{C}$ of the corresponding toluene or hexane solutions. On the other hand, a fraction of solid of $\mathbf{5}$ was dissolved in hexane and the solution was then allowed to slowly evaporate at room temperature to give dark green crystals. Single crystals were coated with mineral oil and mounted on Mitegen MicroMounts with the aid of a microscope and immediately placed in the low temperature nitrogen stream of the diffractometer. The intensity data sets were collected at $200 \mathrm{~K}$ on a Bruker-Nonius KappaCCD diffractometer equipped with graphite-monochromated Mo K $\alpha$ radiation $(\lambda=0.71073 \AA)$ and an Oxford Cryostream 700 unit. Crystallographic data for all complexes are presented in Table S1 in the Supporting Information.

Most crystals of complexes $\mathbf{2 - 5}$ and 9 diffract poorly above $\theta \approx 25^{\circ}$. In that sense, refinement could only be performed up to $25^{\circ}$, except in the case of 3 that used data with $\theta$ from 3 to $27.5^{\circ}$. The structures were solved, by using the WINGX package, ${ }^{16}$ by direct methods (SHELXS-2013 for complexes $\mathbf{2}, \mathbf{3}$, and $\mathbf{9})^{17}$ or intrinsic phasing (SHELXT-2014 for 4, and 5) ${ }^{18}$ and refined by least-squares against $\mathrm{F}^{2}$ (SHELXL-2014). ${ }^{19}$

Unit cell of compound 4 presented two crystallographic independent molecules in the asymmetric unit. Crystals of $\mathbf{2}$, and $\mathbf{3}$ crystallized with three or two toluene solvent molecules, respectively, but it was only possible to get a sensible chemical model for one of them in the case of $\mathbf{2}$, although the carbon atom of the methyl group had to be refined isotropically. The Squeeze ${ }^{20}$ procedure of the PLATON package was employed to remove the contribution of that electronic density to the structure factors. Additionally, in the case of complex $\mathbf{3}$, it was not possible to 
unequivocally determine the identity of the $\mu_{3}$-bridging atoms, thus $\mathrm{S} 4$ and $\mathrm{Cl} 5$ bridging atoms were refined with the aid of the EXYZ and EADP Shelx's commands to obtain occupancies of $47.81 \%$ and $52.19 \%$, respectively. EADP constraints were also applied to the ring carbon atoms of the two pentamethylcyclopentadienyl ligands to suppress some alerts in checkcif.

All the hydrogen atoms were positioned geometrically and refined by using a riding model while all the non-hydrogen atoms were refined anisotropically.

Computational details. Electronic structure calculations were performed using the PBE0 density functional ${ }^{21,22,23}$ and the $\operatorname{Def} 2-\mathrm{SV}(\mathrm{P})$ basis set for all atoms and associated pseudopotential for $\mathrm{Ta}^{24,25}$ Geometry optimizations were performed with D3 version of Grimme's dispersion with Becke-Johnson damping, ${ }^{26}$ and all stationary points were optimized by computing analytical energy gradients. The obtained minima were characterized by performing energy second derivatives, confirming them as minima by the absence of negative eigenvalues of the Hessian matrix of the energy. Transition states were characterized by single imaginary frequency, whose normal mode corresponded to the expected motion. To further refine the energies obtained from the PBE0/Def2-SV(P) calculations, single-point calculations were performed using the larger Def2-TZVP basis set. ${ }^{24}$ Since the computed Hessians of a couple of optimized structures were found to posses small negative eigenvalues, the zero-point vibrational effects and thermal energy corrections were not included in the final energies. All calculations were performed with the Gaussian 09 suite of programs. ${ }^{27}$ 


\section{RESULTS AND DISCUSSION}

The trimetallic sulfide cluster $\left[\mathrm{Ta}_{3}\left(\eta^{5}-\mathrm{C}_{5} \mathrm{Me}_{5}\right)_{3} \mathrm{Cl}_{3}\left(\mu_{3}-\mathrm{Cl}\right)(\mu-\mathrm{S})_{3}\left(\mu_{3}-\mathrm{S}\right)\right]$ (2) was prepared in a similar manner as the recently reported cube-type sulfide clusters $\left[\mathrm{MCl}(\mathrm{NR}) \operatorname{py}\left(\mu_{3}-\mathrm{S}\right)\right]_{4}(\mathrm{M}=\mathrm{Nb}$, $\left.\mathrm{Ta} ; \mathrm{R}={ }^{t} \mathrm{Bu}, 2,6-\mathrm{Me}_{2} \mathrm{C}_{6} \mathrm{H}_{3}\right) .{ }^{12}$ Treatment of $\left[\mathrm{Ta}\left(\eta^{5}-\mathrm{C}_{5} \mathrm{Me}_{5}\right)_{3} \mathrm{Cl}_{4}\right]$ (1) with $\left(\mathrm{Me}_{3} \mathrm{Si}\right)_{2} \mathrm{~S}$ (3:4 ratio) in toluene heating at $100{ }^{\circ} \mathrm{C}$ for 72 hours produced cleanly 2 , as a yellowish green microcrystalline solid along with $\mathrm{SiClMe}_{3}$, as outlined in Scheme 1.

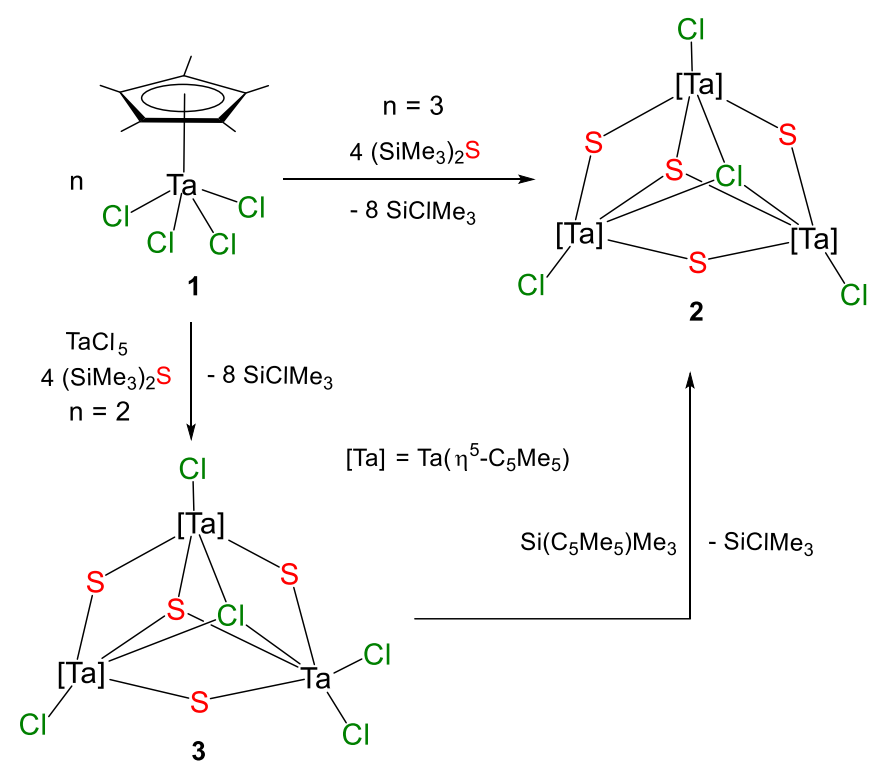

Scheme 1. Synthesis of the trinuclear tantalum complexes 2 and $\mathbf{3}$.

Regardless of the selectivity of this process, during the examination under the microscope of a portion of crystals of $\mathbf{2}$, from one of the several reactions carried out to obtain this complex, unexpectedly we were able to identify by X-ray diffraction a new species structurally characterized as the trimetallic sulfide cluster $\left[\mathrm{Ta}_{3}\left(\eta^{5}-\mathrm{C}_{5} \mathrm{Me}_{5}\right)_{2} \mathrm{Cl}_{4}\left(\mu_{3}-\mathrm{Cl}\right)(\mu-\mathrm{S})_{3}\left(\mu_{3}-\mathrm{S}\right)\right](\mathbf{3})$. In an attempt to synthesize and isolate compound $\mathbf{3}$ in pure form, the one-pot reaction between $\mathbf{1}$, $\mathrm{TaCl}_{5}$ and $\left(\mathrm{Me}_{3} \mathrm{Si}\right)_{2} \mathrm{~S}$ in 2:1:4 ratio was carried out, providing 3 as an emerald green solid after stirring in toluene at room temperature for several days (see Scheme 1). Fortunately, the 
trinuclear complex $\mathbf{3}$ is less soluble in toluene than the tiny amount of $\mathbf{2}$ also produced along the course of the reaction, so the two complexes could be separated by filtration to give analytically pure $\mathbf{3}$ in $70 \%$ yield. Furthermore, the addition of one equivalent of trimethyl(pentamethylcyclopentadienyl)silane to a $\mathrm{C}_{6} \mathrm{D}_{6}$ solution of complex 2 in an NMR tube essay afforded complex $\mathbf{3}$ in a quantitative way, as outlined in Scheme 1.

Compound $\mathbf{2}$ is discretely soluble in the usual solvents such as hexane, benzene, toluene, tetrahydrofurane or chloroform, while $\mathbf{3}$ is hardly soluble in hydrocarbon solvents and soluble in chlorinated solvents (dichloromethane, chloroform). Both species were characterized by elemental analysis as well as spectroscopic data, IR and NMR, and the molecular structures of 2 and $\mathbf{3}$ were unambiguously determined by X-ray analysis. ORTEP drawings are given in Figure

1.

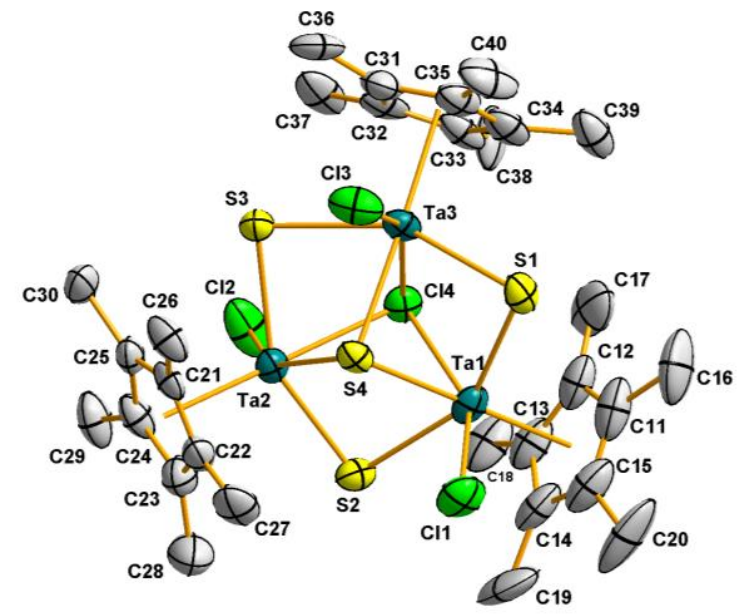

2

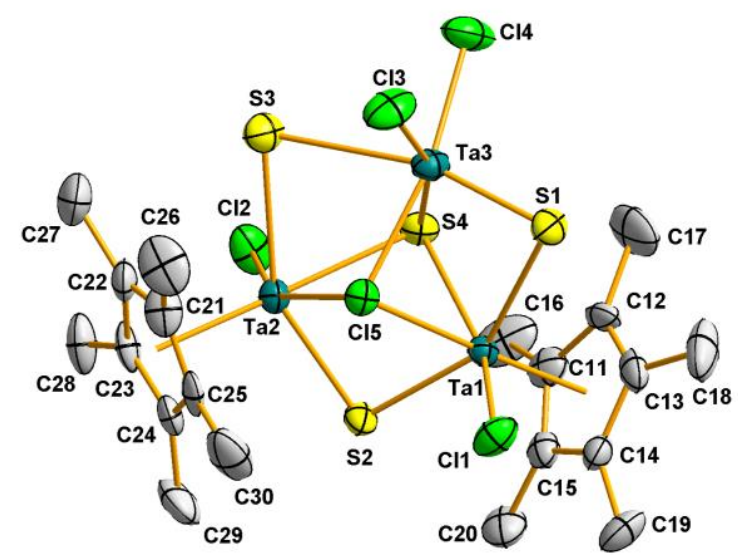

3

Figure 1. Molecular structure of compounds 2 and 3. Thermal ellipsoids are at $50 \%$ probability. Hydrogen atoms are omitted for clarity. Ranges or averaged values for selected lengths $(\AA)$ and

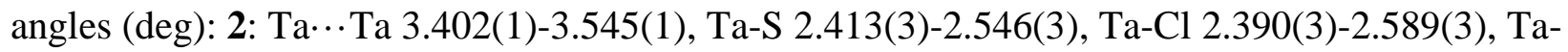
Cl4-Ta 86.1(1)-88.9(1), $\quad \mathrm{S}_{\mathrm{eq}}-\mathrm{Ta}-\mathrm{S}_{\mathrm{eq}} \quad$ 149.7(1)-150.3(1), $\quad \mathrm{S}_{\mathrm{eq}}-\mathrm{Ta}-\mathrm{S} 4 \quad 75.1(1)-82.0(1), \quad \mathrm{Ta}-\mathrm{S}-\mathrm{Ta}$ 


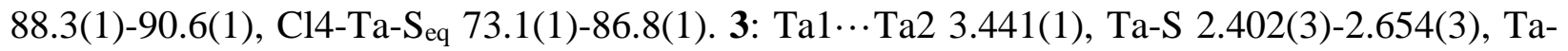

Cl 2.386(2), Ta1-S2-Ta2 91.3(1), Cl-Ta-S eq 87.2(1)-99.3(1), $\mathrm{S}_{\text {eq }}-\mathrm{Ta} 1 / \mathrm{Ta} 2-\mathrm{S}_{\text {eq }}$ 149.4(2).

As shown in Figure 1, the X-ray studies of $\mathbf{2}$ and $\mathbf{3}$ revealed a triangular arrangement of tantalum atoms with long $\mathrm{Ta}{ }^{\cdots} \mathrm{Ta}$ distances close to $3.40 \AA$, according with no direct metalmetal bond between the Ta centers. The Ta $\mathrm{Ta}_{3}$ triangle is capped by one $\mu_{3}-\mathrm{S}$ and one $\mu_{3}-\mathrm{Cl}$ atoms and additionally, to fulfill a slightly distorted octahedral environment, each tantalum center is bonded to one pentamethylcyclopentadienyl ligand, a chlorine and two bridging sulfur atoms, except Ta3 in $\mathbf{3}$, linked to two chlorine atoms and two bridging sulfur atoms. The total valence electrons for these complexes are 48 for compound $\mathbf{2}$ and 44 for complex 3 with the three metal centers in maximum oxidation state. Although a few trinuclear chalcogenide cluster structures were previously identified by X-ray crystallography with tantalum, ${ }^{28,29,30}$ often as part of complex product mixtures, discrete sulfur clusters cores like $\mathrm{Ta}_{3}\left(\mu_{3}-\mathrm{S}\right)(\mu \text {-S })_{3}$ were unknown until now.

The three $\left[\mathrm{Ta}\left(\eta^{5}-\mathrm{C}_{5} \mathrm{Me}_{5}\right)_{1-\mathrm{x}} \mathrm{Cl}_{1+\mathrm{x}}\right](\mathrm{x}=0,1)$ moieties are linked by sulfur atoms forming a nearly planar $\mathrm{Ta}_{3} \mathrm{~S}_{3}$ ring. As can be seen in complex 2 (see Figure 1), two of the chlorine atoms and one $\eta^{5}-\mathrm{C}_{5} \mathrm{Me}_{5}$ ligand are situated above this plane, while the third chlorine atom and the other two $\eta^{5}-\mathrm{C}_{5} \mathrm{Me}_{5}$ groups lie below it. The ${ }^{1} \mathrm{H}$ NMR spectrum in $\mathrm{C}_{6} \mathrm{D}_{6}$ of $\mathbf{2}$ shows one unique resonance at $\delta 1.90$ for the pentamethylcyclopentadienyl rings, at significantly higher field compared with the starting compound $\mathbf{1}\left(\mathrm{C}_{6} \mathrm{D}_{6}, \delta=2.15\right)$. The same trend is observed in the ${ }^{13} \mathrm{C}$ spectrum, where the resonances for these groups are at $\delta 123.6$ and 12.1. Although the solidstructure shown for $\mathbf{2}$ in Figure 1 is in agreement with a $C_{1}$ symmetry, the presence of one rather than two peaks in 1:2 ratio for the pentamethylcyclopentadienyl ligands in the NMR spectra suggests the existence of a dynamic behavior in solution. However, no change of the spectra took 
place upon lowering the temperature from room temperature to $-80{ }^{\circ} \mathrm{C}$. In contrast, the room temperature ${ }^{1} \mathrm{H}$ NMR spectrum of complex 3 in $\mathrm{CDCl}_{3}$ shows two sharp singlets at 2.45 and 2.41 ppm with an 1:1 intensity ratio, assigned to the inequivalent pentamethylcyclopentadienyl rings, compatible with the solid-state structure.

The scope of this work was to obtain multimetallic sulfide precursors in low oxidation states capable to activate small molecules in mild conditions. In an attempt to reduce the isolated trinuclear derivatives $\mathbf{2}$ and $\mathbf{3}$, several reducing agents, such as $\mathrm{Na} / \mathrm{Hg}, \mathrm{Mg}, 1,4-$ bis(trimethylsilyl)-1,4-diaza-2,5-cyclohexadiene or $\mathrm{SiH}_{3} \mathrm{Ph}$, were used. Whereas the reactions of complex $\mathbf{3}$ gave complex mixtures of products, surprisingly, all reactions carried out with 2 afforded the diamagnetic dimetallic tantalum(IV) sulfide derivative $\left[\mathrm{Ta}_{2}\left(\eta^{5}-\mathrm{C}_{5} \mathrm{Me}_{5}\right)_{2} \mathrm{Cl}_{2}(\mu-\mathrm{S})_{2}\right]$ (4), as determined later by X-ray diffraction analysis and DFT calculations (vide infra). Thermal treatment of compound 2 with $\mathrm{SiH}_{3} \mathrm{Ph}$ at $\approx 100{ }^{\circ} \mathrm{C}$ for several days provided 4 as a dark red solid in high yield, as outlined in Scheme 2. Thus, $\mathrm{SiH}_{3} \mathrm{Ph}$ was the best reducing agent for generating the low-valent metal complex 4. Moreover, monitoring an NMR tube scale reaction of 2 with $\mathrm{SiH}_{3} \mathrm{Ph}$ in $\mathrm{C}_{6} \mathrm{D}_{6}$ solution at room temperature by ${ }^{1} \mathrm{H}$ NMR spectroscopy revealed $\mathrm{H}_{2}(\delta 4.46)$ and $\mathrm{SiClH}_{2} \mathrm{Ph}(\delta 5.06)$ formation along with other volatile unidentified silane products. Complex 4 has been characterized by NMR spectroscopy, elemental analysis, and single-crystal X-ray diffraction, as discussed below. On the other hand, 4 can be easily synthesized by one-pot reaction of $1,\left(\mathrm{Me}_{3} \mathrm{Si}\right)_{2} \mathrm{~S}$ and $\mathrm{SiH}_{3} \mathrm{Ph}$ in toluene as well.

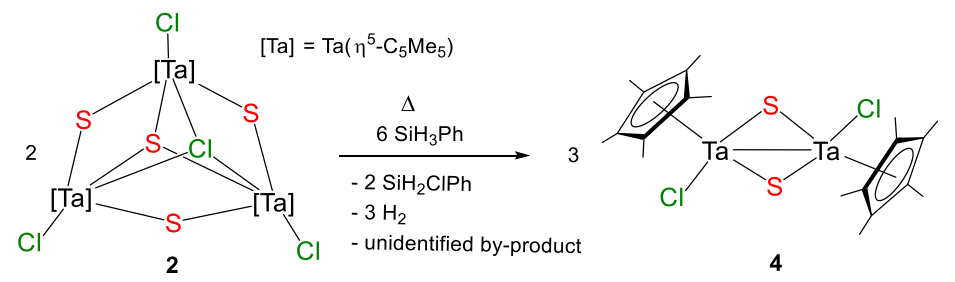

Scheme 2. Synthesis of sulfur-bridged tantalum complex 4. 
In order to move forward with our study on these compounds having metal-sulfur cores, we next investigated the reactivity of complex 4 in metathesis reactions. A series of dinuclear tantalum(IV) peralkylated sulfide complexes, $\left[\mathrm{Ta}_{2}\left(\eta^{5}-\mathrm{C}_{5} \mathrm{Me}_{5}\right)_{2} \mathrm{R}_{2}(\mu-\mathrm{S})_{2}\right]\left(\mathrm{R}=\mathrm{Me} \mathbf{5}, \mathrm{CH}_{2} \mathrm{Me} \mathbf{6}\right.$, $\mathrm{CH}_{2} \mathrm{SiMe}_{3}$ 7, $\mathrm{C}_{3} \mathrm{H}_{5}$ 8, Ph 9), were synthesized in moderate-high yields. These reactions proceeded smoothly by treatment of 4 with 2 equiv of $\mathrm{LiCH}_{2} \mathrm{SiMe}_{3}$ or $\mathrm{MgClR}\left(\mathrm{R}=\mathrm{Me}, \mathrm{CH}_{2} \mathrm{Me}\right.$, $\mathrm{C}_{3} \mathrm{H}_{5}, \mathrm{Ph}$ ) at room temperature in toluene or hexane, as outlined in Scheme 3. All complexes were spectroscopically characterized and, in case of $\mathbf{5}$ and $\mathbf{9}$, crystallographically as well.

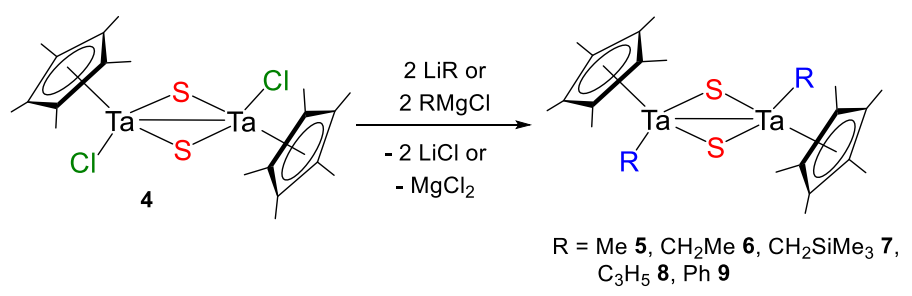

Scheme 3. Preparation of dinuclear tantalum alkyl sulfide complexes 5-9.

X-ray quality crystals were obtained by cooling of a concentrated toluene solution of 4,5 and 9 to $-20{ }^{\circ} \mathrm{C}$. The molecular structures are shown in Figure 2, and selected bond distances and angles are listed in Table 1. The molecular structures of these complexes consist of two $\mathrm{Ta}\left(\eta^{5}-\right.$ $\left.\mathrm{C}_{5} \mathrm{Me}_{5}\right) \mathrm{X}(\mathrm{X}=\mathrm{Cl}, \mathrm{R})$ units bridged by two sulfur atoms, in which the short Ta $\cdots$ Ta distances between 2.918(1)-2.951(1) $\AA$ are in the range found for other ditantalum complexes with bonding interaction between the two tantalum centers, ${ }^{31}$ and are significantly shorter than those observed in the trinuclear species $\mathbf{2}$ and $\mathbf{3}$ (vide supra). The existence of an inversion center in the middle of the molecule leads to locate the two $\eta^{5}-\mathrm{C}_{5} \mathrm{Me}_{5}$ and chloro or alkyl ligands in mutually trans orientation. The averaged distances Ta-Cl of 2.342(3) $\AA$ and Ta-S of 2.32(3) $\AA$ are also shorter than those found in the trimetallic complexes 2 and 3. $\mathrm{The}^{\mathrm{T}} \mathrm{Ta}_{2} \mathrm{~S}_{2}$ cores show angles close to $102^{\circ}$ (S-Ta-S) and to $78^{\circ}$ (Ta-S-Ta) in agreement with the planar geometry. 

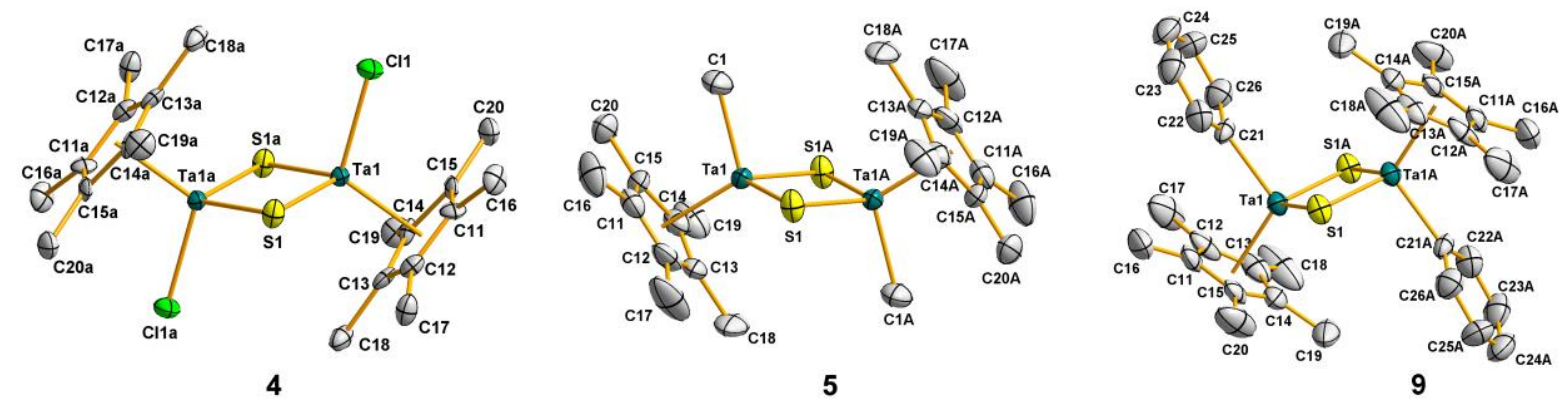

Figure 2. Molecular structures of compounds 4, 5, and 9. Thermal ellipsoids are at 50\% probability. Hydrogen atoms are omitted for clarity.

Table 1. Selected averaged lengths $(\AA)$ and angles $\left(^{\circ}\right)$ for 4,5 , and 9.

\begin{tabular}{lrrr}
\hline Complex & $\mathbf{4}$ & $\mathbf{5}$ & $\mathbf{9}$ \\
\hline $\mathrm{Ta}-\mathrm{S}$ & $2.337(5)$ & $2.331(1)$ & $2.334(2)$ \\
$\mathrm{Ta}-\mathrm{Cl}$ & $2.342(3)$ & & \\
$\mathrm{Ta}-\mathrm{C}$ & & $2.176(9)$ & $2.168(8)$ \\
$\mathrm{Ta} \cdots \mathrm{Ta}$ & $2.948(2)$ & $2.929(1)$ & $2.918(1)$ \\
$\mathrm{Ta}-\mathrm{S}-\mathrm{Ta}$ & $78.2(2)$ & $77.9(1)$ & $77.4(1)$ \\
$\mathrm{S}-\mathrm{Ta}-\mathrm{S}$ & $101.8(2)$ & $102.2(1)$ & $102.6(1)$
\end{tabular}

In order to elucidate the nature of bonding between the two tantalum centers in complexes $\mathbf{4}$, 5 and 9, we performed a DFT study. The DFT calculations revealed that computed Ta $\cdots$ Ta distances were in good agreement with those determined by X-ray diffraction studies for complexes 4, 5 and 9, as shown in Table 2. Furthermore, we performed a molecular orbitals analysis of complex 5 in its trans configuration. The frontier molecular orbitals, HOMO and LUMO, are shown in Figure 3 (see Figure S23 for the cis analogue). The HOMO consists of a $\sigma$ bonding combination between one atomic $\mathrm{d}$ orbital of each tantalum center indicating the existence of a Ta-Ta bond, as suggested by the short distances determined in both X-ray and DFT-optimized structures. 
Table 2. Comparison of Ta-Ta bond distances $(\AA)$ of experimental and calculated structures of complexes 4, 5 and 9.

\begin{tabular}{lccc}
\hline Complex & $\mathbf{4}$ & $\mathbf{5}$ & $\mathbf{9}$ \\
\hline Ta-Ta (exp.) & $2.948(2)$ & $2.929(1)$ & $2.918(1)$ \\
Ta-Ta (calcd.) & 2.977 & 2.954 & 2.928 \\
& & & \\
\end{tabular}

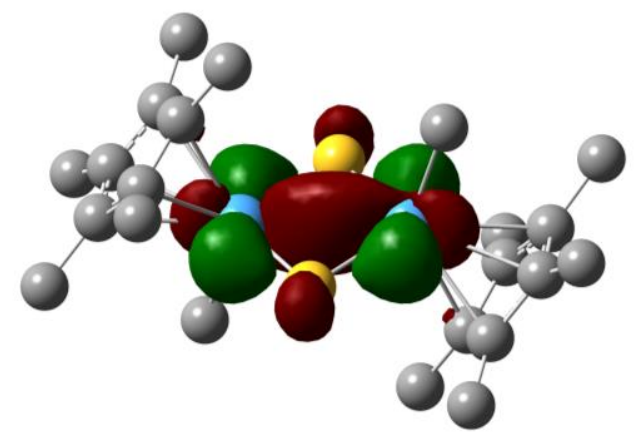

Figure 3. Frontier Molecular orbitals of complex 5 (trans-isomer). HOMO (bottom) and LUMO (top) shown with an isovalue $=0.05$.

The ${ }^{1} \mathrm{H}$ NMR spectra of complexes 4-9 exhibit a single resonance for the $\eta^{5}-\mathrm{C}_{5} \mathrm{Me}_{5}$ ligands in the range $\delta 1.80-2.13$, and reveal symmetric structures in solution according to those found in the solid-state for compounds 4, 5 and 9. The alkyl groups [TaR; $\mathrm{R}=\mathrm{Me}(\mathbf{5}), \mathrm{CH}_{2} \mathrm{Me}(\mathbf{6}), \mathrm{CH}_{2} \mathrm{SiMe}_{3}$ (7)] identified by ${ }^{1} \mathrm{H}$ NMR spectroscopy show signals for the $\alpha$-hydrogens, $-2.21(5),-1.67$ (6), and $-2.80(7) \mathrm{ppm}$, shifted noteworthy upfield with respect to those reported in the literature for the $\mathrm{Ta}(\mathrm{V})$-alkyl species $\left[\mathrm{Ta}\left(\eta^{5}-\mathrm{C}_{5} \mathrm{Me}_{5}\right) \mathrm{R}_{4-\mathrm{x}}(=\mathrm{CHR})_{\mathrm{x}-1}\right]\left(\mathrm{x}=0, \mathrm{R}=\mathrm{Me} ; \mathrm{x}=2, \mathrm{R}=\mathrm{CH}_{2} \mathrm{Ph}\right.$, 
$\left.\mathrm{CH}_{2} \mathrm{SiMe}_{3}\right)^{32,33}$ or $\left[\mathrm{Ta}\left(\eta^{5}-\mathrm{C}_{5} \mathrm{Me}_{5}\right) \mathrm{R}_{2}(\mathrm{NAr})\right]\left(\mathrm{Ar}=2,6-\mathrm{Me}_{2} \mathrm{C}_{6} \mathrm{H}_{3}, \mathrm{R}=\mathrm{Me}, \mathrm{CH}_{2} \mathrm{SiMe}_{3}, \mathrm{CH}_{2} \mathrm{Ph}\right.$, $\left.\mathrm{CH}_{2} \mathrm{CMe}_{2} \mathrm{Ph}, \mathrm{CH}_{2} \mathrm{CMe}_{3}\right) .{ }^{34}$ However, the ${ }^{13} \mathrm{C}\left\{{ }^{1} \mathrm{H}\right\}$ NMR resonances for the alkyl $\alpha$-carbon, $\delta$ $46.8(5), 63.0(6)$, and 61.7 (7), have similar chemical shifts to those found for the mentioned tantalum(V)-alkyl complexes. In the case of complex $\mathbf{8}$, the allyl ligands exhibit the resonances of the well-known $\eta^{1}-\eta^{3}$ isomerization on the NMR timescale at $25^{\circ} \mathrm{C}$, and are characterized by the equivalence of the $\mathrm{CH}_{2}$ groups identified by a doublet at $\delta 1.70(\mathrm{~J}=11 \mathrm{~Hz})$, and a quintuplet at $\delta 5.19(\mathrm{~J}=11 \mathrm{~Hz})$ for the $\mathrm{CH}$ groups, characteristic of a dynamic behavior. The resonances for the methyne and methylene carbons appear at $\delta 77.0$ and 109.9 respectively. The lowtemperature ${ }^{1} \mathrm{H}$ NMR spectra of 8 performed between room temperature and $-90{ }^{\circ} \mathrm{C}$ does not show the split of the doublet; only a significant broadening and a downfield chemical shift of the signal are observed (see Figures S19 and S20).

To understand this experimental feature, we decided to study, with the aid of density functional theory calculations, how the relative arrangement of the allyl group affects to the stability of the complex. The species containing both allyl ligands with a $\eta^{1}$ coordination is computed to be thermochemically the least stable isomer and its transformation to that with a $\eta^{3} / \eta^{1}$ mixed configuration is a favorable process and occurs with almost no kinetic barrier, as it can be seen in Figure 4. The most favored coordination mode is an $\eta^{3}$-arrangment for both allyl groups, although the energy difference between the $\eta^{3} / \eta^{1}$ and $\eta^{3} / \eta^{3}$ configurations is quite small ( $3 \mathrm{kcal} / \mathrm{mol}$ ), as shown in Figure 4. Moreover, the interconversion between them occurs with a very low kinetic barrier, indicating that both configurations can be engaged in a dynamic equilibrium at room temperature or below, in agreement with that observed in the ${ }^{1} \mathrm{H}$ NMR spectra. 


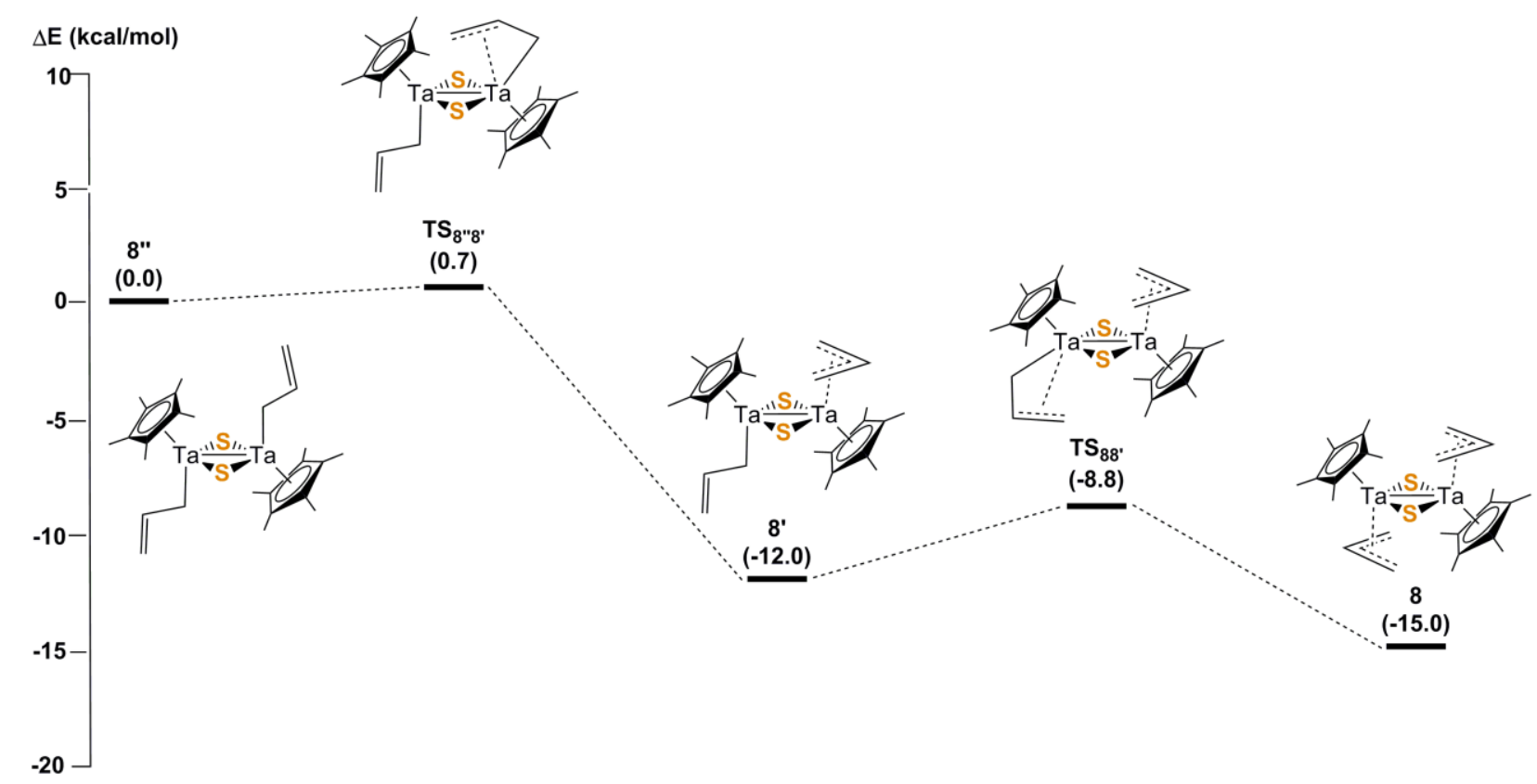

Figure 4. Schematic energy profile $\left(\mathrm{kcal} \cdot \mathrm{mol}^{-1}\right)$ for the $\eta^{1}-\eta^{3}$ rearrangements in complex 8 .

Solutions of the alkyl complexes $\mathbf{7 , 8}$ and $\mathbf{9}$ in $\mathrm{C}_{6} \mathrm{D}_{6}$ are stable for days at room temperature or heating up to $65^{\circ} \mathrm{C}(\mathbf{8})$ or up to $120^{\circ} \mathrm{C}(7$ and 9). In contrast, when solutions of 5 and 6 are heated, other analogue complete set of signals slightly shifted from the initial resonances are observed upon monitoring by ${ }^{1} \mathrm{H}$ NMR spectroscopy. These experimental features led us to think about the existence of a trans to cis conversion process in solution for complexes $\mathbf{5}$ and $\mathbf{6}$, and it was studied by ${ }^{1} \mathrm{H}$ NMR spectroscopy increasing the temperature up to $95{ }^{\circ} \mathrm{C}$ and using both transparent and amberized NMR tubes (Figures S9, S10, S13 and S14). In case of complex 5, we were able to see that initially only trans complex was present in both experiments and only in the case of the expermients performed with a transparent NMR tube, the cis complex slowly appeared indicating that the isomerization occured only photochemically. An analogous study was followed with complex 6, and the appearance of the cis derivative is observed in both 
experiments performed with transparent or amberized NMR tubes confirming that, for $\mathbf{6}$, this process can occur thermally or photochemically under the conditions employed.

The trans-cis isomerization process could be rationalized by DFT calculations. The solid-state structure atomic disposition obtained for complex 5 (Figure 2) was used as a model. As it can be seen in Figure 5, DFT calculations predict a thermoneutral reaction for complex 5, $\Delta \mathrm{E}=0$ $\mathrm{kcal} / \mathrm{mol}$, for the trans to cis conversion in line with the coexistence of both isomers as observed experimentally by NMR spectroscopy (vide supra). Two different transition states in the singlet and triplet electronic states were found for this isomerization. In both transition states, one of the metal centers acquires a square-planar geometry that would allow the interchange between the methyl and pentamethylcyclopentadienyl ligands. As it can be seen in Figure 5, the transition state in the triplet state, $\mathbf{T S}_{5}{ }^{\prime} \mathbf{5 a}^{2}$, is located $7 \mathrm{kcal} \cdot \mathrm{mol}^{-1}$ below in energy than the corresponding transition state in the singlet state, $\mathbf{T S}_{55 \mathbf{a}}$. The lower kinetic barrier observed in the triplet potential energy surface as compared to the singlet one can be rationalized by the cleavage of the metal-metal bond in the former state, thus, allowing an easier rotation around the $\mathrm{Ta} \cdots \mathrm{Ta}$ axis. Both isomers cis and trans are in the ground singlet spin state but the isomerization process is accelerated $^{35}$ taking place via a triplet potential energy surface by spin crossover at two subsequent points of the reaction coordinate (Figure 5). The activation barrier computed of 43.4 $\mathrm{kcal} \cdot \mathrm{mol}^{-1}$ is high enough to prevent the reaction from occurring at an appreciable rate in the absence of light across the temperature range of study in agreement with experimental evidences (see above) where the trans-cis isomerization process was observed to occur photochemically at temperatures up to $95^{\circ} \mathrm{C}$. 


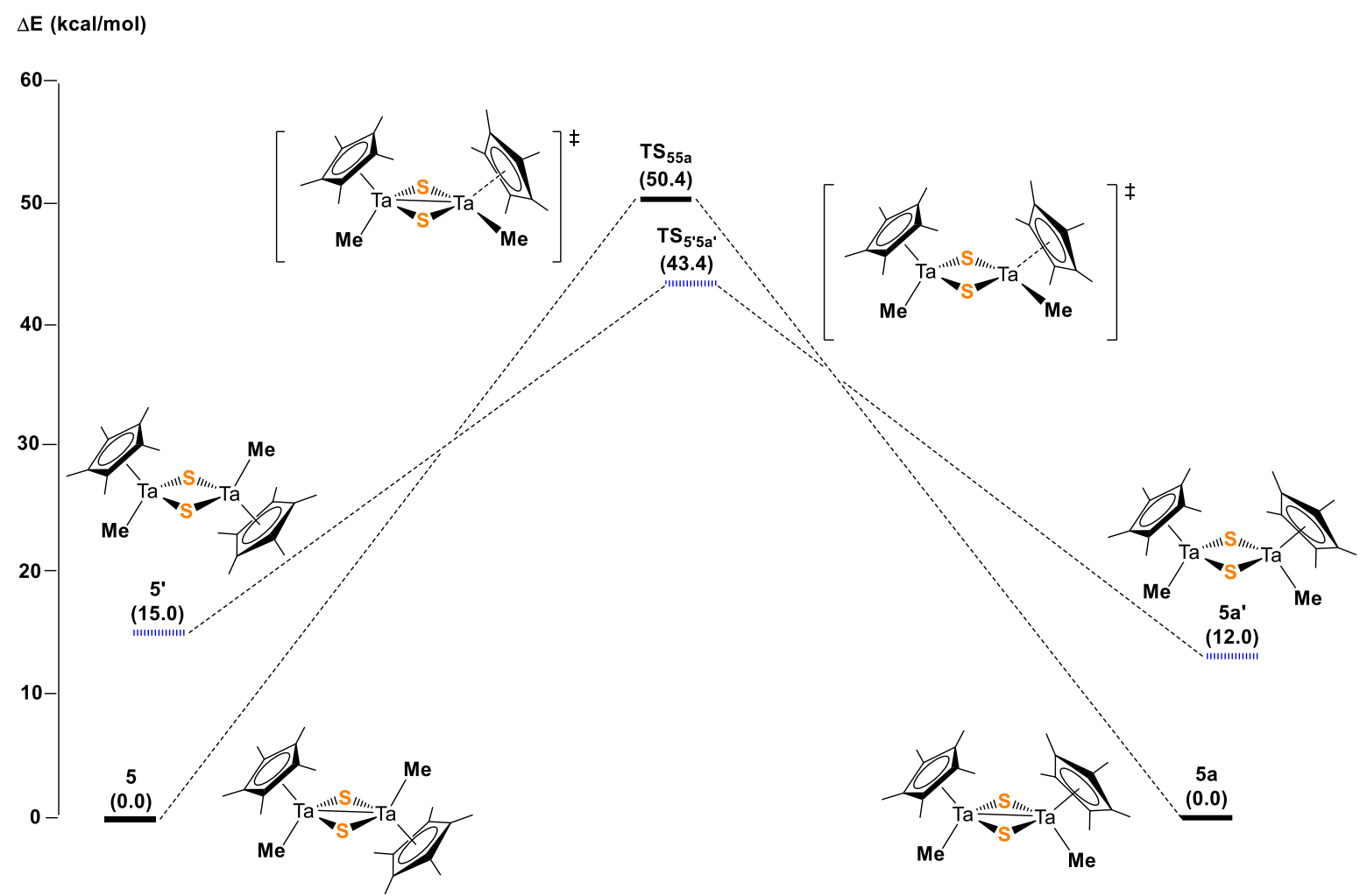

Figure 5. Schematic energy profile $\left(\mathrm{kcal} \cdot \mathrm{mol}^{-1}\right)$ for the trans-cis isomerization process for complex 5 .

As stated above, in contrast to that observed for complex 5, the trans to cis isomerization of complex $\mathbf{6}$ occurs thermally. The isomerization computed for complex $\mathbf{6}$ is similar to that computed for complex 5 with just a slightly lower barrier $\left(\Delta E^{\ddagger}=41.5 \mathrm{kcal} \cdot \mathrm{mol}^{-1}\right.$, see Figure S24 in Supplementary Information). Nevertheless, for the case of complex $\mathbf{6}$, the presence of $\beta$ hydrogen atoms in the alkyl ligands led us to consider the $\beta$-elimination process as an alternative pathway (see Figure 6). After overcoming a moderate energy barrier of $18.9 \mathrm{kcal} \cdot \mathrm{mol}^{-1}$ associated to $\mathbf{T S} 6 \mathbf{1 1}$, the process yields intermediate $\mathbf{I}_{1}$, which shows an hydride and an olefin group on the same metal center. This species can easily revert back to regenerate complex 6 or alternatively, it can isomerize to the corresponding cis intermediate $\mathbf{I}_{2}$ surmounting transition states TS1/112 or TS21112 (depending on the sense of the twist) with a square base pyramid 
geometry around the tantalum center containing the alkene and hydride ligands. Once $\mathbf{I}_{2}$ is obtained, the olefin insertion into the metal-hydride bond occurs with a minor kinetic barrier to generate the final cis isomer 6a. Similarly to what was observed for the isomerization of complex 5, the $\mathbf{6}$ to $\mathbf{6 a}$ transformation occurs with $\Delta E=-2.0 \mathrm{kcal} \cdot \mathrm{mol}^{-1}$, in agreement with the possibility to have both species in an equilibrium as observed by NMR spectroscopy and discussed above. However, the activation barrier computed for the transformation of complex $\mathbf{6}$ according to the mechanism shown in Figure $6\left(\Delta E^{\ddagger}=30.4 \mathrm{kcal} \cdot \mathrm{mol}^{-1}\right)$ is about $13 \mathrm{kcal} \cdot \mathrm{mol}^{-1}$ lower than in the case of the isomerization observed for complex $\mathbf{5}$ in Figure 5. Thus, the presence of $\beta$-hydrogens in the alkyl groups of complex $\mathbf{6}$ facilitates the trans to cis isomerization by reducing considerably the activation energy by the successive $\beta$-elimination, rotation, and alkene insertion steps and this is consistent with the observation of the isomerization of complex 6 in the absence of light.

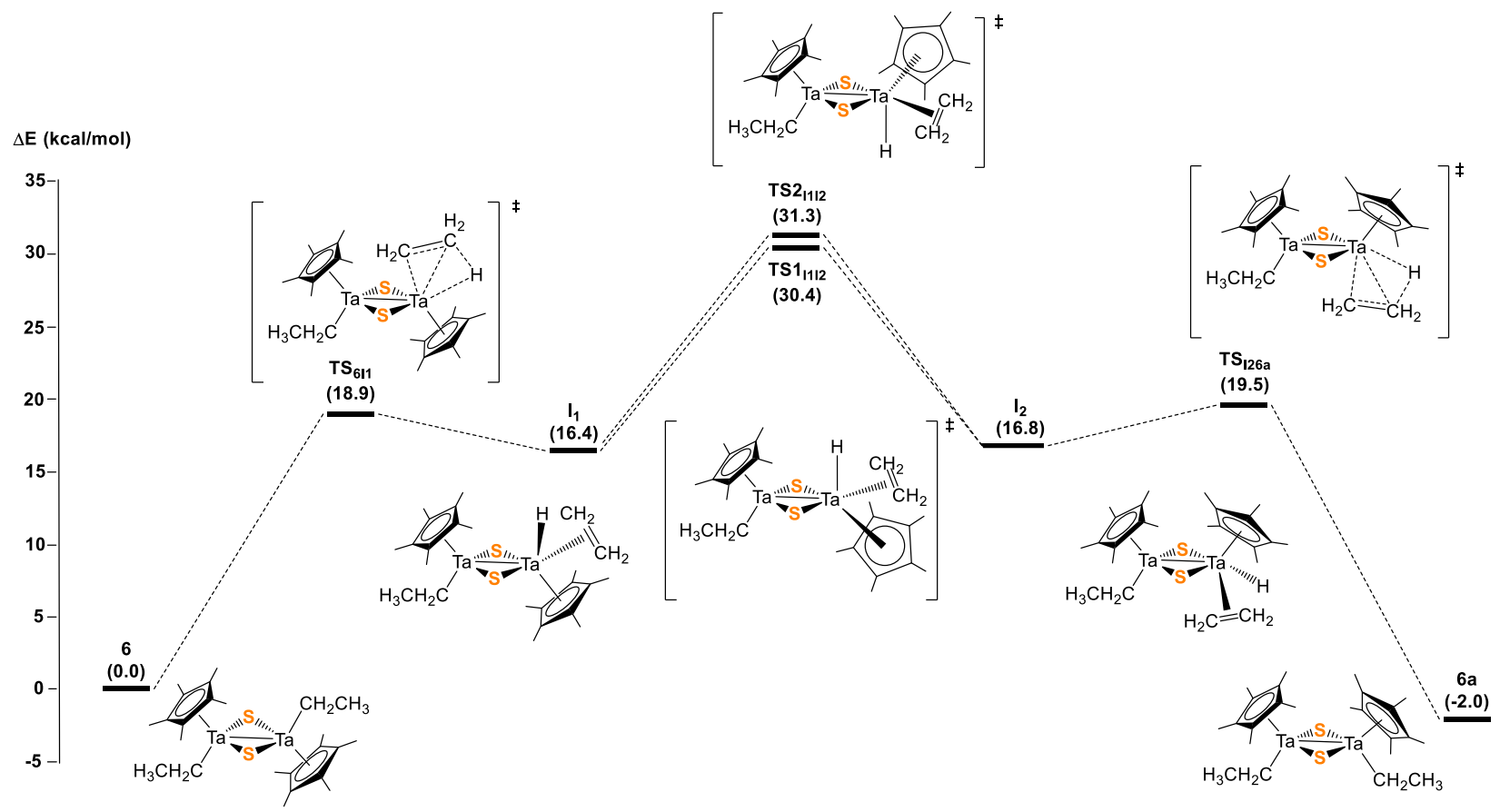

Figure 6. Schematic energy profile $\left(\mathrm{kcal} \cdot \mathrm{mol}^{-1}\right)$ for the trans-cis isomerization process for $\mathbf{6}$. 
Indirect evidence for the presence of the species hydride-olefin $\mathbf{I}_{1}$ in this process was obtained experimentally. Thus, the monitoring by ${ }^{1} \mathrm{H}$ NMR spectroscopy of a benzene- $\mathrm{d}_{6}$ solution of $\mathbf{6}$ in presence of 1-hexene ( 1 equiv.) and subsequent heating at $\approx 65^{\circ} \mathrm{C}$ revealed free ethylene ( $\left.\delta 5.24\right)$. Moreover, transition metal hydride-olefin complexes of group 5 are known, and in most cases limited to those complexes bearing two cyclopentadienyl ligands. ${ }^{36,37}$

On the other hand, due to the oxidation state of the metal centers, we have also optimized each geometry in the triplet state and checked their energy. In this case, the triplet state has a higher energy content than the singlet ground state in each step. In fact, the transition states strictly analogous to TS1 $1_{1112}$ and $\mathbf{T S 2} 2_{1112}$ optimized in the triplet state are 29.2 and $31.2 \mathrm{kcal} \cdot \mathrm{mol}^{-1}$ higher in energy than their singlet counterparts respectively. Thus, in opposition to mechanism discussed above for complex $\mathbf{5}$, the metal-metal bond is maintained without breaking during the isomerization process in complex 6.

\section{CONCLUSIONS}

A series of di- and trinuclear cyclopentadienyl sulfide tantalum complexes have been synthesized, in which the presence of the cyclopentadienyl ligand significantly enhances the synthesis, characterization and further reactivity of the complexes formed. Trans-cis isomerization reactions were evidenced in some of the dinuclear complexes, and DFT calculations enabled us to propose mechanisms for these unexpected processes. The trans-cis isomerization for $\left[\mathrm{Ta}_{2}\left(\eta^{5}-\mathrm{C}_{5} \mathrm{Me}_{5}\right)_{2} \mathrm{R}_{2}(\mu \text {-S })_{2}\right]$ complexes occurs photochemically when $\mathrm{R}=\mathrm{Me}$

and thermally when $\mathrm{R}=\mathrm{CH}_{2} \mathrm{Me}$. The presence of $\beta$-hydrogen atoms in the latter facilitates the isomerization by occurring in consecutive $\beta$-elimination, rotation, and alkene insertion steps what reduces considerably the activation energy as compared to the one step process observed in 
the case of $\left[\mathrm{Ta}_{2}\left(\eta^{5}-\mathrm{C}_{5} \mathrm{Me}_{5}\right)_{2} \mathrm{Me}_{2}(\mu-\mathrm{S})_{2}\right]$. By applying the synthetic protocol followed here with tantalum, further studies are now in progress with other elements of group 5.

\section{ASSOCIATED CONTENT}

\section{Supporting Information}

The following files are available free of charge.

Table of crystallographic data for $\mathbf{2 - 5}$, and 9 (Table S1).

NMR spectra for complexes 2-9 (Figures S1-S22).

Frontier Molecular Orbitals for complex 5 (cis-isomer) (Figure S23).

Energy profile for trans-cis isomerization process for complex 6 (Figure S24)

Cartesian coordinates for theoretical calculations (XYZ).

\section{Accession Codes}

CCDC 1884934-1884938 contain the supplementary crystallographic data for this paper. These data can be obtained free of charge via www.ccdc.cam.ac.uk/data_request/cif, or by emailing data_request@ccdc.cam.ac.uk, or by contacting The Cambridge Crystallographic Data Centre, 12 Union Road, Cambridge CB2 1EZ, UK; fax: +44 1223336033.

\section{AUTHOR INFORMATION}

\section{Corresponding Author}

*Email: cristina.santamaria@uah.es

\section{Notes}

The authors declare no competing financial interest. 


\section{ACKNOWLEDGMENT}

Financial support for this work was provided by the Ministerio de Economía y Competitividad

(CTQ2013-44625-R) and the Universidad de Alcalá (CCG2017-EXP/036). C. H.-P. and J. I. G-P thank the Universidad de Alcalá for a predoctoral fellowship.

\section{REFERENCES}

(1) Holm, R. H.; Ciurli, S.; Weigel, J. A. In Progress in Inorganic Chemistry: Bioinorganic Chemistry; Lippard, S. J. (Ed.) John Wiley \& Sons, 1990, 38, 1-74.

(2) Holm, R. H. Trinuclear Cuboidal and Heterometallic Cubane-Type Iron-Sulfur Clusters: New Structural and Reactivity Themes in Chemistry and Biology. Adv. Inorg. Chem. 1992, $38,1-71$.

(3) Münck, E.; Bominaar, E. L. Bringing Stability to Highly Reduced Iron-Sulfur Clusters. Science 2008, 321, 1452-1453.

(4) Harris, S. Structure, Bonding and Electron Counts in Cubane-Type Clusters Having $\mathrm{M}_{4} \mathrm{~S}_{4}$, $\mathrm{M}_{2} \mathrm{M}_{2}{ }_{2} \mathrm{~S}_{4}$ and $\mathrm{MM}_{3} \mathrm{~S}_{4}$ Cores. Polyhedron 1989, 8, 2843-2882.

(5) Synthesis and Reactivities of Cubane-Type Sulfido Clusters Containing Noble Metals. Hidai, M.; Kuwata, S.; Mizobe, Y. Acc. Chem. Res. 2000, 33, 46-52.

(6) Llusar, R.; Uriel, S. Heterodimetallic Chalcogen-Bridged Cubane-Type Clusters of Molybdenum and Tungsten Containing First-Row Transition Metals. Eur. J. Inorg. Chem. 2003, 1271-1290.

(7) Howard, J. B; Rees, D. C. Structural Basis of Biological Nitrogen Fixation. Chem. Rev. 1996, 96, 2965-2982.

(8) Burgess, B. K.; Lowe, D. J. Mechanism of Molybdenum Nitrogenase. Chem. Rev. 1996, 96, 2983-3011.

(9) Rauchfuss, T. B. Research on Soluble Metal Sulfides: From Polysulfido Complexes to Functional Models for the Hydrogenases. Inorg. Chem. 2004, 43, 14-26.

(10) a) Wachter J. Bis(cyclopentadienyl Transition Metal) Complexes Rich in Sulfur, J. Coord. Chem., 1987, 15, 219-236. b) Wachter, J. Synthesis, Structure and Reactivity of SulfurRich Cyclopentadienyl-Transition Metal Complexes: Sulfur Chemistry from an Organometallic Point of View. Angen. Chem. Int. Ed. Engl. 1989, 28, 1613-1626.

(11) DuBois, M. R.; Jagirdar, B.; Noll, B.; Dietz S. In Transition Metal Sulfur Chemistry. Stiefel, E., et al. (Ed.) ACS Symposium Series, 1996, chapter 16, 270-281. 
(12) Gómez, M.; Hernández-Prieto, C.; Martín, A.; Mena, M.; Santamaría C. Systematic Approach for the Construction of Niobium and Tantalum Sulfide Clusters. Inorg. Chem. 2016, 55, 3815-3821.

(13) Hidalgo Llinás, G; Mena, M.; Palacios, F.; Royo, P.; Serrano, R. ( $\left.\mathrm{C}_{5} \mathrm{Me}_{5}\right) \mathrm{SiMe}_{3}$ as a Mild and Effective Reagent for Transfer of the $\mathrm{C}_{5} \mathrm{Me}_{5}$ Ring: An Improved Route to Monopentamethylcyclopentadienyl Trihalides of the Group 4 Elements. J. Organomet. Chem. 1998, 340, 37-40.

(14) Tessier-Youngs, C.; Beachley JR, O. T. In Inorganic Syntheses; Shreeve, J. Ed. John Wiley \& Sons, Inc. 1986, Vol 24, Chapter 2, pp 95-97.

(15) Sulzbach, R. A.; Iqbal, A. F. M. 1,4-Bis(trimethylsilyl)-1,4-dihydropyrazine by Reductive Silylation of Pyrazine. Angew. Chem. Int. Ed. 1971, 10, 127-127.

(16) Farrugia, L. J. WinGX and ORTEP for Windows: an update. J. Appl. Cryst. 2012, 45, 849854.

(17) Sheldrick, G. M. A Short History of SHELX. Acta Cryst. 2008, A64, 112-122.

(18) Sheldrick, G. M. SHELXT-Integrated Space-Group and Crystal-Structure Determination. Acta Cryst. 2015, A71, 3-8.

(19) Sheldrick, G. M. Crystal Structure Refinement with SHELXL. Acta Cryst. 2015, C71, 3-8.

(20) Spek, A. L. PLATON SQUEEZE: A Tool for the Calculation of the Disordered Solvent Contribution to the Calculated Structure Factors. Acta Cryst. 2015, C71, 9-18.

(21) Perdew, J. P.; Burke, K.; Ernzerhof, M. Generalized Gradient Approximation Made Simple. Phys. Rev. Lett. 1996, 77, 3865-3868. ERRATA Perdew, J. P.; Burke, K.; Ernzerhof, M. Generalized Gradient Approximation Made Simple [Phys. Rev. Lett. 77, 3865 (1996)]. Phys. Rev. Lett. 1997, 78, 1396-1396.

(22) Adamo, C.; Barone, V. Toward Reliable Density Functional Methods Without Adjustable Parameters: The PBE0 model. J. Chem. Phys. 1999, 110, 6158-6170.

(23) Ernzerhof, M.; Scuseria, G. E. Assessment of the Perdew-Burke-Ernzerhof ExchangeCorrelation Functional. J. Chem. Phys. 1999, 110, 5029-5036.

(24) Weigend, F.; Ahlrichs, R. Balanced Basis Sets of Split Valence, Triple Zeta Valence and Quadruple Zeta Valence Quality for H to Rn: Design and Assessment of Accuracy. Phys. Chem. Chem. Phys. 2005, 7, 3297-3305. (b) Weigend, F. Accurate Coulomb-Fitting Basis Sets for H to Rn. Phys. Chem. Chem. Phys. 2006, 8, 1057-1065.

(25) Weigend, F. Accurate Coulomb-Fitting Basis Sets for H to Rn. Phys. Chem. Chem. Phys. 2006, $8,1057-1065$.

(26) Grimme, S.; Ehrlich, S.; Goerigk, L. Effect of the Damping Function in Dispersion Corrected Density Functional Theory. J. Comp. Chem. 2011, 32, 1456-1465. 
(27) Gaussian 09, Revision D.01, Frisch, M. J.; Trucks, G. W.; Schlegel, H. B.; Scuseria, G. E.; Robb, M. A.; Cheeseman, J. R.; Scalmani, G.; Barone, V.; Mennucci, B.; Petersson, G. A.; Nakatsuji, H.; Caricato, M.; Li, X.; Hratchian, H. P.; Izmaylov, A. F.; Bloino, J.; Zheng, G.; Sonnenberg, J. L.; Hada, M.; Ehara, M.; Toyota, K.; Fukuda, R.; Hasegawa, J.; Ishida, M.; Nakajima, T.; Honda, Y.; Kitao, O.; Nakai, H.; Vreven, T.; Montgomery, Jr., J. A.; Peralta, J. E.; Ogliaro, F.; Bearpark, M.; Heyd, J. J.; Brothers, E.; Kudin, K. N.; Staroverov, V. N.; Kobayashi, R.; Normand, J.; Raghavachari, K.; Rendell, A.; Burant, J. C.; Iyengar, S. S.; Tomasi, J.; Cossi, M.; Rega, N.; Millam, J. M.; Klene, M.; Knox, J. E.; Cross, J. B.; Bakken, V.; Adamo, C.; Jaramillo, J.; Gomperts, R.; Stratmann, R. E.; Yazyev, O.; Austin, A. J.; Cammi, R.; Pomelli, C.; Ochterski, J. W.; Martin, R. L.; Morokuma, K.; Zakrzewski, V. G.; Voth, G. A.; Salvador, P.; Dannenberg, J. J.; Dapprich, S.; Daniels, A. D.; Farkas, Ö.; Foresman, J. B.; Ortiz, J. V.; Cioslowski, J.; Fox, D. J. Gaussian, Inc. Wallingford CT, 2013.

(28) Fenske, D.; Maué, P. G. Zur Reaktion von $\left[\eta^{5}-\mathrm{CpMCl}_{4}\right]\left(\mathrm{M}=\mathrm{Nb} \text {, Ta) mit E( } \mathrm{SiMe}_{3}\right)_{2}(\mathrm{E}=$ $\mathrm{S}, \mathrm{Se})$. Die Kristallstrukturen von $\left[\mathrm{Cp}_{8} \mathrm{Ta}_{6} \mathrm{~S}_{10}\right]\left[\mathrm{TaSCl}_{5}\right],\left[\mathrm{Cp}_{3} \mathrm{Ta}_{3} \mathrm{~S}_{7} \mathrm{Cl}_{2}\right],\left[\mathrm{Cp}_{4} \mathrm{Ta}_{4} \mathrm{Si}_{3}\right]$ und $\left[\mathrm{Cp}_{3} \mathrm{Nb}_{3} \mathrm{Se}_{5} \mathrm{Cl}_{2}\right]$. Z. Naturforsch. 1989, 44b, 531-537.

(29) Tatsumi, K.; Inoue, Y.; Kawaguchi, H.; Kohsaka, M.; Nakamura, A.; Cramer, R. E.; VanDoorne, W.; Taogoshi, G. J.; Richmann P. N. Structural Diversity of Sulfide Complexes Containing Half-Sandwich $\mathrm{Cp}^{*} \mathrm{Ta}$ and $\mathrm{Cp} * \mathrm{Nb}$ fragments. Organometallics 1993, 12, 352-364.

(30) a) Kawaguchi, H.; Tatsumi, K. Synthesis of (Pentamethylcyclopentadienyl)tantalum Sulfido Complexes Via C-S Bond Cleavage of Triphenylmethanethiolate and Formation of a Novel Trithioborato Ligand. Organometallics 1997, 16, 307-309. b) Kar, S.; Saha, K.; Saha, S.; Kirubakaran, B.; t Dorcet, V.; Ghosh, S. Trimetallic Cubane-Type Clusters: Transition-Metal Variation as a Probe of the Roots of Hypoelectronic Metallaheteroboranes. Inorg. Chem. 2018, 57, 10890-10905.

(31) Ghosh S.; Roy, D. K. In Molecular Metal-Metal Bonds. Compounds, Syntheses, Properties. Liddle, S. T. (Ed.) Wiley-VCH Verlag GmbH \& Co. 2015, 91-138.

(32) Messerle, L. W.; Jennische, P.; Schrock, R. R.; Stucky G. Preparation of Monocyclopentadienyl Benzylidene Complexes of Tantalum and the Crystal Structure of $\mathrm{Ta}\left(\eta^{5}-\mathrm{C}_{5} \mathrm{Me}_{5}\right)(\mathrm{CHPh})\left(\mathrm{CH}_{2} \mathrm{Ph}\right)_{2}$. J. Am. Chem. Soc. 1980, 102, 6744-6752.

(33) de Castro, I.; de la Mata, J.; Gómez, M.; Gómez-Sal, P.; Royo, P.; Selas, J. M. Monocyclopentadienyl Alkyl Alkylideneniobium(V) and Tantalum(V) Complexes. X-Ray Crystal Structure of Ta $\left(\eta^{5}-\mathrm{Cp}{ }^{\prime}\right)\left(\mathrm{CH}_{2} \mathrm{SiMe}_{3}\right)_{2}\left(\mathrm{CHSiMe}_{3}\right)$. Polyhedron 1992, 11, 1023-1027.

(34) Castro, A.; Galakhov, M. V.; Gómez, M.; Gómez-Sal P., Martín, A.; Royo P. Alkyl Chloro, Dialkyl and Mixed Alkyl Derivatives of Imido(pentamethylcyclopentadienyl) tantalum(V). X-Ray Crystal Structure of [TaCp*Cp'Cl\{N(2,6- $\left.\left.\left.\mathrm{Me}_{2} \mathrm{C}_{6} \mathrm{H}_{3}\right)\right\}\right],\left(\mathrm{Cp}^{\prime}=\eta^{5}-\right.$ $\mathrm{C}_{5} \mathrm{H}_{4} \mathrm{SiMe}_{3}$ ]. J. Organomet. Chem. 1998, 554, 185-194. 
(35) Smith, K. M.; Poli, R.; Havey, J. N. Ligand dissociation accelerated by spin state change: locating the minimum energy crossing point for phosphine exchange in $\mathrm{CpMoCl}_{2}\left(\mathrm{PR}_{3}\right)_{2}$ complexes. New. J. Chem. 2000, 24, 77-80.

(36) Klazinga, A. H.; Teuben, J. H. Synthesis and Properties of Dicyclopentadienyltantalum Hydride Olefin Compounds. J. Organomet. Chem. 1978, 157, 413-419, and references herein.

(37) Burger, B. J.; Santarsiero, B. D.; Trimmer, M. S.; Bercaw, J. E. Kinetics and Mechanism of the Insertion of Olefins into Niobium- and Tantalum-Hydride Bonds: A Study of the Competition Between Steric and Electronic Effects. J. Am. Chem. Soc. 1988, 110, 31343146. 


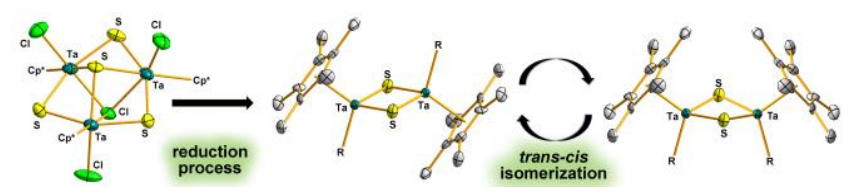

The presence of the cyclopentadienyl ligand significantly enhances the synthesis, characterization and further reactivity of a series of di- and trinuclear cyclopentadienyl sulfide tantalum complexes. Some of the dinuclear derivatives exhibit trans-cis isomerization and DFT calculations enabled us to propose mechanisms for these unexpected processes. 